\title{
Regulating high-cost short-term credit in the UK: is there scope for 'libertarian paternalism' based provisions?
}

\author{
Abdul Karim Aldohni ${ }^{1 *}$ (1) and Darren Duxbury ${ }^{2 \dagger}$ (B) \\ ${ }^{1}$ Newcastle Law School and ${ }^{2}$ Newcastle University Business School, Newcastle University, UK \\ ${ }^{\star}$ Corresponding author. email: a.k.aldohni@ncl.ac.uk
}

(Accepted 19 May 2021)

\begin{abstract}
The regulatory protection of credit consumers, in general, is paramount due to the considerable use of credit, the imbalanced bargaining positions of the contracting parties and the adverse effect of over-indebtedness on individuals and society alike. These concerning factors are worsened in the case of High-Cost Short-Term Credit (HCSTC) consumers owing to their disadvantaged financial position and other recognised vulnerabilities. In this respect, the paper argues that direct regulatory intervention, despite its importance, is not always a silver bullet. Through the analysis of the overhauling of the UK HCSTC regulatory framework, this paper demonstrates the shortfalls of these regulatory changes. Accordingly, the paper shifts the argument towards improving the decision-making mechanisms of HCSTC consumers, ie the role of 'libertarian paternalism'based interventions. By using a bespoke experimental survey, the paper demonstrates the type of behavioural interventions that can assist in this endeavour and which the regulator could possibly mandate.
\end{abstract}

\section{Introduction}

Although the 2008 financial crisis originated in the banking and financial sector, its impacts have been felt, beyond the financial market, in the day-to-day life of ordinary citizens in the UK due to the budget cuts and austerity measures that followed. ${ }^{1}$ The 2008 financial crash brought noticeable change to the regulatory side of the financial sector, where new regulators were created and sweeping changes were made to the underlying regulatory framework. Even the landscape of the UK financial market has changed since, with the disappearance of some of its main regional players, such as Northern Rock in the North East of England, ${ }^{2}$ the partial nationalisation of some of the major institutions in the banking market such as the Royal Bank of Scotland, ${ }^{3}$ and the break-up of some of the large banking institutions such as Lloyds TSB. ${ }^{4}$ Further, the financial market witnessed a proliferation in HCSTC providers, who enjoyed a period of lax regulation and provided a much-needed service. They supplemented those ordinary citizens with limited access to mainstream lending with credit, yet their practices at times were widely exploitative and came at a hefty price. $^{5}$

\footnotetext{
${ }^{\dagger}$ The authors would like to thank the anonymous reviewers for their helpful comments and Citizen Advice Newcastle for administering the surveys.

${ }^{1}$ Oxfam 'The true cost of austerity and inequality: UK case study' (September 2013), https://www-cdn.oxfam.org/s3fspublic/file_attachments/cs-true-cost-austerity-inequality-uk-120913-en_0.pdf.

${ }^{2}$ National Audit Office 'HM Treasury: nationalisation of Northern Rock' (20 March 2008) https://www.nao.org.uk/pressrelease/hm-treasury-the-nationalisation-of-northern-rock-2/; 'Northern Rock sold to Virgin Money' (BBC, 17 November 2011), https://www.bbc.co.uk/news/business-15769886\#: :text=Northern\%20Rock\%20is\%20being\%20sold,job\%20cuts\%20for\% 20three\%20years.

${ }^{3} \mathrm{PT}$ Larsen 'UK launches $£ 37$ bn bank rescue' (Financial Times, 13 October 2008).

${ }^{4} \mathrm{R}$ Jones 'TSB returns to the high street as Lloyds splits its branches' (The Guardian, 8 September 2013).

${ }^{5} \mathrm{~S}$ Goff 'Crisis boosts growth in payday loans sector' (Financial Times, 6 December 2011).

(c) The Author(s), 2021. Published by Cambridge University Press on behalf of The Society of Legal Scholars. This is an Open Access article, distributed under the terms of the Creative Commons Attribution licence (http://creativecommons.org/licenses/by/4.0/), which permits unrestricted re-use, distribution, and reproduction in any medium, provided the original work is properly cited.
} 
After taking over the regulation of consumer credit in 2014, the FCA brought comprehensive changes to the HCSTC regulatory framework in an attempt to address some of the concerning aspects of HCSTC. However, evidence remains that the HCSTC sector is still posing significant risks to its consumers. Therefore, it is argued in this paper that the regulator should reconsider its approach to the protection of HCSTC consumers. It is suggested that behavioural economics, more specifically 'libertarian paternalism', could have a role to play in influencing the behaviour of HCSTC consumers and helping improve their borrowing decisions.

Accordingly, Part 1 of the paper examines the composition of the UK consumer credit market with particular focus on HCSTC. It highlights the HCSTC growth post 2008, exposes its danger and examines the regulatory response. Part 2 analyses the impact of the sweeping changes brought by the FCA to the HCSTC regulatory framework, highlighting the remaining persistent dangers to consumers and arguing the need to further develop the regulatory approach to this sector. Part 3 advocates a need to rethink the regulatory response and proposes a 'libertarian paternalism' approach as a potential complementary solution. Part 4 reports the results of an experimental survey designed and administered in collaboration with Citizens Advice to evaluate the effectiveness of 'libertarian paternalism' in the context of the HCSTC. Part 5, based on findings of the bespoke experimental survey, introduces the 'libertarian paternalism'-based provision that could improve the borrowing decisions of HCSTC consumers, while also highlighting an approach to be avoided.

\section{Understanding the UK consumer credit market, HCSTC lenders and the regulatory evolution}

Relatively recent figures show that the second largest net borrowing sector in the UK (ie spent more than received in income) were households, at $1.6 \%$ of GDP. ${ }^{6}$ The total household debt in 2018 was $£ 1,785$ billion compared to $£ 1,455$ billion in 2008 . These figures refer to borrowing generally, which includes credit secured on dwellings (mortgages) and consumer credit. The Bank of England defines consumer credit 'as borrowing by UK individuals to finance current expenditure on goods and/or services excluding loans issued by the Student Loans Company'? In this respect, the UK has the biggest consumer credit market among its neighbouring EU countries, followed by Germany and France. ${ }^{8}$ In January 2019, the monthly average of consumer credit borrowing was esti-

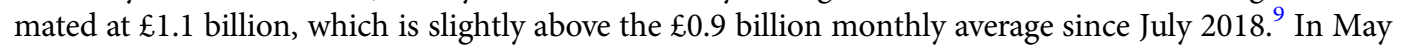
2019 , the outstanding consumer credit was estimated at $£ 217.3$ billion. ${ }^{10}$ At the household level, the ratio of unsecured debt to household income is expected to reach $45 \%$ by $2021 .{ }^{11}$ At the individual level, the figures published in 2018 by the Bank of England showed that their measure of total outstanding debt to individuals rose by an annual rate of $3.8 \%$ with $7.5 \%$ rise in unsecured debt. ${ }^{12}$

These figures provide useful insights into the levels of consumer credit borrowing in the UK. They demonstrate the substantial size of the UK consumer credit market, which indicates its central role in the British economy as an important means to facilitate a wide range of consumers' spending. They also provide evidence of the continuous and steady growth of this sector since the global financial crisis of 2008. While these figures do not factor in the devastating effect of the Covid-19 pandemic on low-income households and individuals, it seems wholly likely that a further growth in the sector will follow.

The UK consumer credit market has a complicated landscape. The market is primarily made of two main types of credit: first, mainstream credit that includes various forms among which are bank

\footnotetext{
${ }^{6}$ Office for National Statistics 'Quarterly sector accounts, UK: July to September 2018' (December 2018) p 5.

${ }^{7}$ Bank of England 'Further details about total lending to individuals data' (14 February 2019).

${ }^{8}$ Financial Services User Group 'Responsible consumer credit lending: FUGS opinion and recommendations for the review of the Consumer Credit Directive' (2019) p 4.

${ }^{9}$ Bank of England 'Money and credit - September 2019'.

${ }^{10}$ The Money Charity 'The money statistics' (July 2019) p 5.

${ }^{11}$ Office for Budget Responsibility 'Recent trends in consumer credit' (March 2017).

${ }^{12} \mathrm{D}$ Harari 'Household debt: statistics and impact on economy' House of Commons, Briefing Paper No 7584 (21 December 2018) p 10.
} 
account overdrafts, personal loans, credit cards; ${ }^{13}$ secondly, high-cost credit, also known as subprime credit. This category includes a range of products which are usually offered to a class of consumers considered as less creditworthy and this category encompasses: home-collected credit, catalogue credit, pawn broking, logbook loan and - most importantly for the purpose of this paper -HCSTC, also widely known as payday lending. ${ }^{14}$

The 2008 financial crash brought some significant changes to the consumer credit market in the UK at the operational and regulatory levels. With regard to operational aspects, the consumer credit market went from a state of overdrive in the run-up to 2008 , where credit was not only widely available but also remarkably cheap, to a state of regression post the 2008 financial crash. The mainstream credit providers found themselves in a difficult position where credit was no longer widely and cheaply available on the interbank market. Therefore, they had to respond to the market conditions and adjust their business model, which meant applying far more stringent lending criteria. This reaction was not only due to a shortage in supply, but it was also driven by the regulatory measures - micro prudential provisions - imposed by the financial authorities, primarily on mainstream credit providers, as a response to the failures of 2008.

Accordingly, consumers' access to credit, in general, became very restricted. However, the most affected ones were those with very limited access to mainstream credit even before the 2008 financial crash. The new market conditions made it virtually impossible for them to access mainstream credit. Borrowers with low rating on the creditworthiness scale posed an immediate risk to mainstream credit providers, to be avoided. At the same time, the financial position of this group of borrowers was worsened by the cuts and austerity measures brought in by consecutive UK Governments since 2008, which consequently increased their need for credit. ${ }^{15}$ The combination of an increased demand for credit and a restricted access to mainstream borrowing resulted in the proliferation of high-cost credit providers, more specifically HCSTC providers, who filled this gap - albeit at a very hefty price that reached $4214 \%$ APR in November $2012 .^{16}$

There are several facts that help provide a clear picture of the scale of HCSTC expansion in the UK consumer credit market. First, HCSTC lending increased from approximately $£ 100$ million in 2004 to $£ 1.9$ billion in $2010 .{ }^{17}$ Secondly, the number of consumers using HCSTC increased from 0.3 million in 2006 to 1.2 million in 2009, and to 1.9 million in $2010 .^{18}$ Thirdly, it was estimated that by March 2014 there were 400 HCSTC providers operating in the UK consumer credit market. ${ }^{19}$

The extortionate interest rate charged by HCSTC lenders was not the only concerning aspect of their business. Between 2008 and 2012 there was an outcry by campaigners for the regulator at the time, the Office of Fair Trading (OFT), to look into the malpractices of the HCSTC industry, which included: giving loans without first checking adequately that the borrower can afford to repay them, inappropriately targeting particular groups of people with clearly unsuitable or unaffordable credit, rolling over loans so that charges escalate and the loans become unaffordable, and treating unfairly those borrowers who get into financial difficulties. ${ }^{20} \mathrm{~A}$ survey conducted by the campaign

\footnotetext{
${ }^{13}$ National Audit Office 'Regulating consumer credit' (December 2012) p 14.

${ }^{14}$ FCA 'Call for input: high-cost credit including review of the high-cost short-term credit price cap' (November 2016$)$ p 8.

${ }^{15} \mathrm{AK}$ Aldohni 'The UK new regulatory framework of high-cost short-term credit: is there a shift towards a more 'law and society' based approach?' (2017) 40(3) Journal of Consumer Policy 321.

${ }^{16}$ APR calculation factors certain variants in the total cost of credit including the interest rate and other payable charges, however, it does not include default charges: the Financial Services and Markets Act 2000 (Regulated Activities) (Amendment) (No 2) Order 2013, SI 2013/1881, art 21(gg); FCA Handbook, Consumer Credit Sourcebook, CONC App 1.2.3 (R)5. See National Audit Office, above n 13, p 15.

${ }^{17}$ National Audit Office, above n 13, p 15.

${ }^{18}$ Department for Business, Innovation and Skills Committee, https://www.publications.parliament.uk/pa/cm201012/ cmselect/cmbis/1649/164905.htm\#note46 (last accessed 14 June 2021).

${ }^{19}$ I Smith 'UK subprime lenders retreat from payday loans' (Financial Times, 5 April 2017).

${ }^{20}$ OFT 'OFT launches review into payday lending' (24 February 2012) https://webarchive.nationalarchives.gov.uk/ 20131101180011/http://oft.gov.uk/news-and-updates/press/2012/11-12 (last accessed 14 June 2021).
} 
group Which ? $^{21}$ showed that $45 \%$ of those who were surveyed and used HCSTC had rolled over their loans at least once and $57 \%$ were encouraged by HCSTC providers to take out further HCSTC. ${ }^{22}$ In addition, there were some alarming figures published by the National Debtline with regard to the scale of the problem. In the first three months of 2012 the National Debtline received 4,725 calls for help with payday loans, $58 \%$ more than the previous quarter and $133 \%$ more than the same quarter in $2011^{23}$

As for the post-2008 changes in the UK consumer credit market at the regulatory level, it can be suggested that the most significant regulatory change was the transfer of the regulatory responsibilities of the consumer credit market, including HCSTC, from the OFT to the Financial Conduct Authority (FCA) in April 2014.

In this regard, the FCA inherited the reviewing process of the consumer credit market - more specifically HCSTC - that the OFT initiated in February 2012 by launching its review into the malpractices of HCSTC lenders. ${ }^{24}$ In March 2013 the OFT published Payday Lending Compliance Review: Final Report (OFT 2013 report), in which it confirmed some of the abusive practices that riddled the industry. The report found that the identified malpractices were systemic and not 'confined to a few rogue traders'. ${ }^{25}$ Among the abusive practices was, first, irresponsible lending. The OFT review encountered evidence of a lack of sufficiency and rigour in assessing creditworthiness and affordability by the majority of HCSTC providers. ${ }^{26}$ Secondly, the OFT 2013 report found that HCSTC lenders continued their irresponsible lending by allowing loan rollovers. HCSTC lenders often encouraged rolling over loans or presented it as a 'feature' of the loan. ${ }^{27}$ It is a practice that earned the HCSTC lenders significant financial benefits, as the report estimated that $50 \%$ of the sector's revenue came from loans rolled over or refinanced. ${ }^{28}$

Although the actual transfer of responsibilities for the consumer credit market, including HCSTC, took place on 1 April 2014, many important preparatory measures were taken in the run-up to this date. First, the Financial Services Act 2012, s 24 (which substituted ss 138-164 of the Financial Services and Markets Act 2000, and inserted s 137C into that Act) empowered the FCA to make rules regarding the cost of credit and duration of credit agreements. Secondly, the Financial Services (Banking Reform) Act 2013, s 131 amended s 137C of the Financial Services and Markets Act 2000 placing a duty on the FCA to protect HCSTC consumers against excessive charges, in other words, a duty to introduce a price cap. Finally, the FCA expressed their broad vision for the consumer credit market in a consultation paper entitled High-level Proposals for an FCA Regime for Consumer Credit in March 2013. ${ }^{29}$ This was followed in October 2013 by a more detailed and comprehensive consultation paper, Detailed Proposal for the FCA Regime for Consumer Credit. In the October 2013 consultation paper, the FCA provided its detailed vision for the governance of the consumer credit market in general, dedicating a whole chapter to the governance of the HCSTC market. ${ }^{30}$

The October 2013 consultation paper included the FCA's measured response to the two main abusive practices in the HCSTC sector, irresponsible lending without the required affordability checks and

\footnotetext{
${ }^{21}$ Which? is a group that campaigns to protect consumer right, reviews products and offers independent advice. See https:// www.which.co.uk/about-which (last accessed 14 June 2021).

${ }^{22}$ Which? surveyed 3,786 people, 301 of whom had taken out payday loans. https://www.which.co.uk/news/2012/05/newwhich-research-exposes-payday-loan-failings-286258/ (last accessed 14 June 2021).

${ }^{23} \mathrm{~L}$ Bachelor 'Payday loan firms agree to voluntary guidelines' (The Guardian, 24 May 2012), https://www.theguardian. com/money/2012/may/24/payday-loan-firms-agree-voluntary-guidelines (last accessed 14 June 2021).

${ }^{24}$ OFT, above n 20.

${ }^{25}$ OFT 'Payday lending compliance review: final report' (March 2013) p 3, https://webarchive.nationalarchives.gov.uk/ 20131213013305/http://oft.gov.uk/shared_oft/Credit/oft1481.pdf, (last accessed 14 June 2021).

${ }^{26}$ Ibid, p 12.

${ }^{27}$ Ibid, pp 14, 15.

${ }^{28} \mathrm{Ibid}$.

${ }^{29}$ FCA 'High-level proposals for an FCA regime for consumer credit' (March 2013), https://www.fca.org.uk/publication/ consultation/cp13-10.pdf (last accessed 14 June 2021).

${ }^{30}$ FCA, above n 29 , ch 6 .
} 
loan rollovers, which were identified in the OFT 2013 report. A host of measures were proposed by the FCA's October 2013 consultation, including capping debt rollover to two times, requiring risk warning on HCSTC financial promotions, requiring HCSTC lenders to provide information on free debt advice before the point of rollover, and capping the price of HCSTC.

On 1 July 2014, the FCA capped the number of HCSTC loan rollovers at two. ${ }^{31}$ Further, the FCA included specific binding rules in its Consumer Credit Sourcebook, Chapter 5 (CONC 5), with regard to responsible lending, creditworthiness and affordability assessments that apply to HCSTC. ${ }^{32}$ According to CONC 5.2A.10R(1) it is mandatory that each firm must undertake the creditworthiness assessment before entering into a credit agreement in order to assess the consumer's credit risk default. More importantly, the HCSTC providers are required by CONC 5.2A.12R to assess the affordability of the credit agreement, taking into account a number of variables, ${ }^{33}$ without 'the repayments having a significant adverse impact on the customer's financial situation'. ${ }^{34}$ The CONC 5 includes other provisions designed to safeguard the effectiveness of the creditworthiness/affordability assessment. ${ }^{35}$

However, the strongest exercise of regulatory powers over the HCSTC market remains, to this day, the FCA's credit price cap. This measure was originally proposed in the 2013 October consultation, ${ }^{36}$ was later subjected to a separate consultation in July $2014^{37}$ and was implemented on 2 January $2015 .^{38}$

The cap applies to various types of interest and charges, which include - but are not limited to interest on credit, late payment/default charge, transmission charge, early repayment, refinancing or termination charge, credit brokers charge when it is of the same group as the lender or where the credit broker agreed to share the charge with the lender, ancillary services charges, and interest on any of the mentioned charges. ${ }^{39}$ The cap also applies to any charges under 'connected agreements', ${ }^{40}$ and it provides an outright prohibition on 'compound interest'. ${ }^{41}$ It is worth noting that the price cap prevents firms from entering a HCSTC agreement, ${ }^{42}$ imposing charges under a HCSTC agreement, ${ }^{43}$ and operating an electronic system in relation to lending under a HCSTC agreement, ${ }^{44}$ in breach of the price cap rules. It is a three-layer cost cap, structured to deal with all sources of concern in the HCSTC market, namely extortionate interest rates, excessive fees/charges and default charges. ${ }^{45}$ The first layer of

\footnotetext{
${ }^{31}$ FCA Handbook, CONC 6.7.23R and see also 'Detailed rules for the FCA regime for consumer credit including feedback on FCA QCP 13/18 and “made rules” Policy Statement' (February 2014) p 55.

${ }^{32}$ FCA 'Guide for consumer credit firms' (updated February 2016) pp 6-8, https://www.fca.org.uk/publication/finalisedguidance/consumer-credit-being-regulated-guide.pdf (last accessed 14 June 2021).

${ }^{33} \mathrm{CONC}$ 5.2A.12R.

${ }^{34} \mathrm{CONC}$ 5.2A.12R(5).

${ }^{35}$ For instance, CONC 5.2A.36R states that: 'A firm must not accept an application for credit under a regulated credit agreement where the firm knows or has reasonable cause to suspect that the customer has not been truthful in completing the application in relation to information relevant to the creditworthiness assessment'. Further, CONC 5.2A.33 R requires firms to 'establish, implement and maintain clear and effective policies and procedures' in relation to creditworthiness/affordability assessments.

${ }^{36} \mathrm{FCA}$, above n 30, pp 53, 76, 80.

${ }^{37}$ FCA 'Proposals for a price cap on high cost short term credit' (July 2014), https://www.fca.org.uk/static/documents/ consultation-papers/cp14-10.pdf (last accessed 14 June 2021).

${ }^{38}$ FCA 'Detailed rules for the price cap on high cost short term credit including feedback on CP14/10 and final rules' (November 2014), https://www.fca.org.uk/publication/policy/ps14-16.pdf (last accessed 14 June 2021).

${ }^{39}$ ، Ancillary services include, but are not limited to, services related to processing the application and to the transmission of the money being lent, and insurance or insurance-like services ancillary to the agreement' see FCA Handbook, Consumer Credit Sourcebook, 5A.2.17R, 5A.3.21R, 5A.4.17R; FCA Handbook, Consumer Credit Sourcebook, 5A.1.6G.

${ }^{40}$ They are defined in the FCA Handbook, Consumer Credit Sourcebook, CONC 5A.4.16R.

${ }^{41}$ Ibid, 5A.2.19R, 5A.3.24R, 5A.4.19R.

${ }^{42} \mathrm{Ibid}, 5.2 \mathrm{~A}$, the firms that this applies to include HCSTC lending firms and credit brokers.

${ }^{43}$ Ibid, 5.A3. The firms that this applies to include firms lending HCSTC, debt administration firms, debt collection firms and firms operating an electronic HCSTC lending. The meaning of the term 'impose one or more charge' is also clearly defined in 5A.3.

${ }^{44}$ Ibid, 5.4A.

${ }^{45} \mathrm{FCA}$, above n 38 , pp $5-9$.
} 
the cap, the initial price cap, covers interest rates and fees/charges (excluding default charge that is subject to default cap), as HCSTC providers cannot now charge more in interest and fees than $0.8 \%$ per day of the amount borrowed. ${ }^{46}$ The second layer targets default charges as it restricts the amount paid in default to a total of $£ 15$ whether the debt is being repaid in instalments or in a single payment. This means that HCSTC providers cannot charge $£ 15$ for each instance of default when borrowers are paying back by instalments and in any case the cumulative total default charges should not exceed $£ 15 .{ }^{47}$ The third layer is a total cost cap, where a borrower should never pay more in interest, fees and charges than $100 \%$ of the amount borrowed. ${ }^{48}$

\section{Assessing the impact of the regulatory shake up of the HCSTC market since 2014}

As mentioned above, since 2014 the FCA has implemented a host of regulatory interventions, with capping the price of HCSTC being the strongest, to address the grievous problems in this sector. Since then some positive changes, not only in the HCSTC market but also in the practices of its lenders, have been reported. StepChange debt charity published a report in 2017 in which they highlighted a fall in the number of their clients with HCSTC debt problems. It was reported that $23 \%$ of the clients they advised in the first half of 2013 had HCSTC debt problems compared to $16 \%$ of their clients in the first half of $2016 .{ }^{49}$ Further, Citizens Advice reported a fall in the number of HCSTC loans that incurred default charges from 16\% in January 2015 to $8 \%$ in April $2016 .{ }^{50}$ These figures are in line with the findings of the FCA review of the HCSTC market post the price cap, published in July 2017. The data analysis demonstrated a number of positive outcomes: first, an increase in the number of declined applicants, with the majority of them finding retrospectively that the rejection of their HCSTC applications had a positive effect; ${ }^{51}$ secondly, reduction in the revenues of HCSTC providers; and, thirdly, reduction in the numbers of firms operating in the UK market. $^{52}$

However, despite these reported positive changes in the HCSTC sector after the full implementation of the new regulatory framework, there are still some major concerns in relation to the protection of HCSTC consumers. These are due to the evolution of HCSTC products, the use of digital technology and the nature of its consumer base, which require the regulator to develop its regulatory approach accordingly.

It has been reported - not only by debt charities, but also by the FCA - that since the tightening up of the rules and the introduction of the price cap many HCSTC providers have moved to instalments loans. This means instead of requiring a single payment after 30 days, the loans are now repayable typically over 3-4 months. ${ }^{53}$ The change in the product structure explains the decrease in default

\footnotetext{
${ }^{46}$ FCA Handbook, Consumer Credit Sourcebook, 5A.2.3 R, 5A.3.3 R, 5A.4.3 R. see also FCA, above n 38.

${ }^{47}$ Ibid, 5A.2.14R, 5A.3.18R, 5A.4.14R. See also FCA, Policy Statement 14/16 (November 2014).

${ }^{48} \mathrm{Ibid}, 5 \mathrm{~A} .2 .2 \mathrm{R}, 5 \mathrm{~A} .2 .2 \mathrm{R}, 5 \mathrm{~A} .3 .2 \mathrm{R}$. See also FCA Policy Statement 14/16 (November 2014). It is important to note that the introduction of the credit cost cap was essential to address the lack of legal means to challenge the fairness of interest rate in high-cost credit agreements. The 'unfair relationship test' (Consumer Credit Act 1974, ss 140A-140C, which were added by Consumer Credit Act 2006, ss 19-22), was tested unsuccessfully in a number of cases: Robert Shaw v Nine Regions Ltd [2009] EWHC 3514 (QB), Patel v Patel [2009] EWHC 3264 (QB), Nine Regions (t/a Logbook Loans) v Sadeer (14 November 2008) Bromley County Court, Case No 8QT25415 (All England Official Transcript), Nine Regions (t/a Logbook Loans) v Fateh Singh (14 January 2009) Leeds County Court, Claim No 8QZ 16394, and proved to be ineffective in this context.

${ }^{49}$ StepChange debt charity 'Payday loans: the next generation' (2017) p 9.

${ }^{50}$ Citizens Advice 'FCA high-cost credit call for input: Citizen Advice response' (February 2017) p 2.

${ }^{51} 63 \%$ of declined consumers surveyed by the FCA stated they thought it was 'for the best': FCA 'High-cost credit: including review of the high-cost short-term credit price cap' (July 2017) p 12.

${ }^{52} \mathrm{Ibid}, \mathrm{pp}$ 17-22. It is important to note that some of the earlier published literature, such as A Fejos 'Achieving safety and affordability in the UK payday loans market' (2015) 38(2) Journal of Consumer Policy 181, highlighted the potential positive effects of these changes. However, this earlier work did not benefit from the insights that the FCA's 2017 review into HCSTC and the FCA HCSTC lending data provided a few years after the implementations of these measures, and which demonstrated certain new areas of concern in this respect.

${ }^{53} \mathrm{FCA}$, above n 51, p 24 and see also StepChange, above n 49, p 9.
} 
rates, which was earlier identified as one of the positive outcomes of the new regulatory framework. It also explains the rise in the arrears rates, where there is higher risk of missing one instalment, and the increase in the cost of borrowing due to the longer term of the loan. ${ }^{54}$ Further, despite the reported decrease in number of HCSTC consumers seeking help from debt charities, there has been an increase in the number of complaints before the Financial Ombudsmen Services (FOS). The FOS annual report for the year ended 31 March 2019 showed that in 2018/19 they received 25,000 more complaints than they expected, which is nearly double the volume of complaints that they budgeted for. ${ }^{55}$ This is part of 'a substantial and rapid growth in complaints about' this type of credit, which they have been witnessing since $2015 / 2016 .^{56}$ Finally, yet most importantly, despite the earlier discussed regulatory changes, HCSTC remains a major source of over-indebtedness in the UK: $70 \%$ of payday loan borrowers and $50 \%$ of short-term instalments borrowers are over-indebted, compared with only $15 \%$ of UK adults generally. ${ }^{57}$ This is particularly concerning, as: first, relatively recent HCSTC data ${ }^{58}$ published by the FCA has shown a steady increase in the number of HCSTC loans provided between 2016 and 2018; and, secondly, the issue of creditworthiness and affordability checks for HCSTC remains problematic despite the FCA regulatory efforts to tighten up the rules in this respect. ${ }^{59}$ In October 2018, the FCA wrote to the CEOs of HCSTC providers following an increase in complaints about unaffordable lending. The letter reminded them of the FCA requirements of affordable lending, the assessment rules and procedures, and the processes that should be in place to handle the relevant complaints at an institutional level. ${ }^{60}$

Historically, the industrialised economy in the nineteenth century ushered in the social classes as we understand them today, ${ }^{61}$ where a strong correlation between status and authority, on the one hand, and the ownership of economic resources, on the other, was established. ${ }^{62}$ Accordingly, the least economically powerful among the social classes, the working class, relied heavily on high-cost credit to make ends meet, becoming the consumer base of high-cost credit market. O'Connell and Reid have provided a detailed examination of the extensive use of high-cost credit among the working class in the nineteenth century. ${ }^{63}$ Since then high-cost credit providers continued to evolve, with doorstep moneylenders overtaking pawnbrokers as the main source of high-cost credit by the end of the

\footnotetext{
${ }^{54}$ FCA, above n 51, pp 14-15, 23-24.

${ }^{55}$ Financial Ombudsmen Services Annual Report and Accounts for the Year Ended 31 March 2019 pp 24, 29.

${ }^{56}$ Ibid, p 29.

${ }^{57}$ FCA 'Consumer credit: high-cost short-term credit lending data' (updated 15/05/2019).

${ }^{58}$ The FCA produced the analysis based on the new regulatory reporting requirement of Product Sales Data and the FCA Financial Lives Survey 2017. The relevant provisions concerning the reporting requirements in the FCA Handbook, PSD reporting requirement on quarterly basis see SUP 16.11.3R (1-a) and (2-b). For the obligation of HCSTC firms to submit PSD report that contains sales data see SUP 16.11.5R(7). For the obligation of HCSTC firms to ensure that their sales data reports comply with the provisions (ie data items) prescribed in SUP 16 Annex 21R see SIP 16.11.7R. Finally, as to the data items required to be included in PDS report of HCSTC firms see pp 43-45 of SUP 16 Annex 21R.

${ }^{59}$ FCA Handbook, Consumer Credit Sourcebook (CONC), CONC 5.2A.12R, 5.2A.13R, 5.2A.14R, 5.2A.15R, 5.2A.20R. These rules require the firm to assess the customer's ability to repay without the need to borrow to repay, without failing to pay under contractual or statutory obligations and without the repayment having significant adverse impact on their financial position. The rules also require the firm, when savings will be used for the repayment, to take into account the purpose of the savings, their availability at repayment and the impact of using them on the client financial position. The rules prevent the firm, when assessing affordability, from taking into account any indemnity or guarantee, and require them to make a reasonable assessment of the clients' income and expenditure. Finally, the rules draw the extent and scope of the assessment taking into account the nature of the information provided in order to ensure that the assessment is reasonable, dependent and proportionate.

${ }^{60} \mathrm{~J}$ Davidson 'Affordability of HCSTC loans' (Director of Supervision - Retail and Authorisation FCA letter to CEO, 15 October 2018).

${ }^{61} \mathrm{~K}$ Roberts The Working Class (Longman, 1978) p 3.

${ }^{62} \mathrm{JH}$ Goldthorpe 'Social inequality and social integration in modern Britain' in D Wedderburn (ed) Poverty, Inequality and Class Structure (Cambridge: Cambridge University Press, 1974) p 218.

${ }^{63}$ S O'Connell and C Reid 'Working-class consumer credit in the UK, 1925-60: the role of the check trader' (2005) LVIII (2) Economic History Review 378.
} 
twentieth century. ${ }^{64}$ Nowadays, the use of online platforms by HCSTC providers in the $21^{\text {st }}$ century remains the most significant and challenging evolution of all, for a number of reasons.

First, it has considerably helped expand the number of HCSTC borrowers. The Competition and Market Authority (CMA) in its Payday Lending Market Investigation: Final Report exposed the extensive use of online HCSTC providers, with $£ 2.3$ billion worth of HCSTC provided online, amounting to $81 \%$ of the issued HCSTC in $2012 .{ }^{65}$ With almost all online HCSTC providers lending between $£ 100$ and $£ 1000$ (per loan), it is clear that $£ 2.3$ billion worth of HCSTC debt represents a very high number of individual borrowers, even after accounting for borrowers with multiple contemporaneous loans. Despite tightening up the rules of HCSTC, the FCA reported that 5,427,905 HCSTC loans had been given by 30 June $2018 .^{66}$

Secondly, the online platforms and digital technology have changed the demographic and socioeconomic profile of HCSTC consumers. On the one hand, digital technology is classless, which means that the use of the internet, smartphones and tablets is not limited to a particular social class. Undoubtedly, the large demand and fierce competition among rival digital technology companies made these devices relatively attainable for all people. Evidence published by StepChange debt charity showed, in 2016, that HCSTC consumers are 'slightly less likely to be in the most financial vulnerable groups', ie less likely to be on very low income - below $£ 10,000$ a year. ${ }^{67}$ On the other hand, HCSTC is now widely used by younger generations. The FCA has reported that $49.8 \%$ of HCSTC consumers are aged $18-34$ (16.4\% aged $18-24$ and $33.4 \%$ aged $25-34)$ and $20.2 \%$ aged $35-44{ }^{68}$ A large segment within these age groups, millennials aged $24-39$, has been identified by research as highly motivated by consumerism and conspicuous consumption, ${ }^{69}$ and highly dependent on smartphones and digital technology for their social and consumption needs. ${ }^{70}$ It has been suggested that with young adults, mass media, social media arguably, and consumption peer pressure have inflamed their conspicuous consumption traits and weakened self-awareness of their true financial status. ${ }^{71}$ Therefore, the process of boosting their social image - through obtaining products that imply status and convey affluence ${ }^{72}$ relies heavily on obtaining the required credit. ${ }^{73}$ In this regard, it has been suggested that increased income inequalities and economic hardship, which the UK has not been short of since 2008,

\footnotetext{
${ }^{64} \mathrm{D}$ Vincent Poor Citizens: The State and the Poor in Twentieth Century Britain (Longman, 1991) p 186; M Tebbutt Making Ends Meet, Pawnbroking and Working Class Credit (Leicester University Press, 1983) pp 136, 138-167; A Taylor Working Class Credit and Community Since 1918 (Palgrave, 2002) p 58; and S O'Connell Credit and Community: Working Class Debt in the UK since 1880 (Oxford: Oxford University Press, 2009) pp 51-52, 185-187. For more detailed discussion of this period see Aldohni, above n 15 .

${ }^{65} \mathrm{CMA}$ 'Payday lending market investigation: final report' (24 February 2015) p 57, https://assets.publishing.service.gov. uk/media/54ebb03bed915d0cf7000014/Payday_investigation_Final_report.pdf (last accessed 14 June 2021).

${ }^{66}$ FCA, above n 57.

${ }^{67}$ Step Change 'Payday loans: the next generation' (2016) p 11.

${ }^{68} \mathrm{FCA}$, above $\mathrm{n} 57$. These figures are in line with some earlier data published by the StepChange debt charity: almost a quarter of its clients with HCSTC debt (24\%) were under the age of 25 and a 2014 report by the Financial Ombudsman Service showed a spike in the number of consumers complaining about HCSTC and who belong to this age group, more specifically aged 25-35: see Step Change, above n 67, p 11 and Financial Ombudsman Service 'Payday lending: pieces of the picture' (August 2014) p 11, https://www.financial-ombudsman.org.uk/files/1759/payday_lending_report.pdf (last accessed 14 June 2021).

${ }^{69}$ Conspicuous consumption is defined as a 'form of exceptional behaviour ... concerned primarily with the ostentatious display of wealth. Motivated by a desire to impress others with the ability to pay particularly high prices for prestige products, it is a form of consumption which is inspired by the social rather than the economic or physiological utility of products': see R Mason Conspicuous Consumption: A Study of Exceptional Consumer Behaviour (Gower, 1981) pp vii-viii.

${ }^{70} \mathrm{DH}$ Ting et al 'Dependency on smartphone and the impact on purchase behaviour' (2011) 12(3) Young Consumers 193.

${ }^{71}$ TY Sims Muhammad 'Young adults perception and attitude toward conspicuous consumption and poverty' (2012) 8(4) Journal of Social Sciences 513.

${ }^{72}$ A O'Cass and H McEwen 'Exploring consumer status and conspicuous consumption' (2004) 4(1) Journal of Consumer Behaviour 26. See also Y Xu 'The influence of public self-consciousness and materialism on young consumers' compulsive buying' (2008) 9(1) Young Consumers 38.

${ }^{73} \mathrm{~B}$ Kamleitner et al ‘Credit use: psychological perspective on a multifaceted phenomenon' (2012) 47(1) International Journal of Psychology 17.
} 
would enhance the tendency to consume in order to compare to others, while also reducing the attention to the credit cost. ${ }^{74}$ Accordingly, the combination of these identified factors with the 24/7 online accessibility of HCSTC significantly increases the risk of over-indebtedness among younger consumers.

Thirdly, it is well established that, in general, high-cost credit consumers routinely succumb to behavioural biases, such as present bias, instant gratification, over confidence and projection bias. ${ }^{75}$ In the case of HCSTC, the use of online platforms for borrowing makes it almost impossible to minimise these biases. This is due to the instantaneous nature of the process - from application to decision in a few small clicks - which deprives consumers of any reflection time on the decision to borrow. Further, in the case of face-to-face HCSTC borrowing, numerous studies referred to acts of human compassion by the agents of moneylenders who interfered to protect the consumers. ${ }^{76}$ This important human interaction is missing in online HCSTC borrowing as the process is purely mechanical and decisions are entirely based on financial algorithms. Combined with the reported low levels of financial knowledge and confidence in managing money among HCSTC consumers ${ }^{77}$ and the FCA's concerns regarding the rigor of creditworthiness and affordability checks, ${ }^{78}$ the online evolution of HCSTC presents a serious regulatory challenge.

Given that the above identified challenges and dangers persist in the HCSTC market after the tightening up of the rules in the UK, it is argued below that the regulatory approaches to consumer credit, and their underpinning ideology for that matter, have evolved over the years. It is suggested, as a natural step of this regulatory evolution, that the regulator should consider ways to influence consumers' attitudes towards using HCSTC, thereby minimising their exposure to these risks and so enhancing consumer protection. These forms of regulatory interventions are complementary to the substantive regulation and enshrined in behavioural science. They provide preventative means that could influence consumers' choices and help them make better decisions in the first place.

\section{Re-thinking the regulatory approach to the HCSTC market and the suitability of 'libertarian paternalism'}

There is no doubt that the UK regulatory approach to consumer credit, more specifically HCSTC, has come a long way. Gone are the days when the accessibility and transparency of information were central to the regulatory protection of consumers in the context of HCSTC. Nowadays the regulator does not shy away from imposing restrictive provisions to protect HCSTC consumers, as seen in the post-2014 regulatory shake up.

In order to better understand this shift and further advance the argument for regulatory behavioural based interventions (ie libertarian paternalism) we can use Willett's thesis of 'competing ethics' in relation to consumer law, which squarely applies in the context of HCSTC. ${ }^{79}$ Willett argues that there is an ethical spectrum on which consumer law and regulation can be viewed. Towards one

\footnotetext{
${ }^{74}$ Ibid, at 17 .

${ }^{75}$ These are respectively: 'overvaluing recent over the future', 'a driver to use high cost credit options [which were] widely described as convenient and easy and quick in terms of fulfilment', 'over-confidence in [the] ability to maintain payments through the period of the loan', and finally 'underestimating the possibility of change': see S Worton et al 'Usage and experience of high-cost credit: consumer research report' (PwC, May 2018) pp 9-12.

${ }^{76}$ They were cited in O'Connell, above n 64, pp 8, 36, 191. There was some evidence of occasions where those agents knew about the inability of the borrower to pay back and prevented a debtor from taking further credit, or they showed forbearance to a distressed debtor. This is because they cared about establishing trust and friendship within the communities where they operated.

${ }^{77}$ According to the FCA Financial Lives Survey 2017, 61\% of consumers with a payday loan and $41 \%$ of borrowers with short-term instalments loans have low confidence in managing their money, compared with $24 \%$ of all UK adults. Further, $56 \%$ of consumers with a payday loan and $48 \%$ of borrowers with a short-term instalment loan rated themselves as having low levels of knowledge about financial matters: FCA, above n 57.

${ }^{78}$ Davidson, above $\mathrm{n} 60$.

${ }^{79} \mathrm{C}$ Willett 'Re-theorising consumer law' (2018) 77(1) Cambridge Law Journal 179.
} 
end there is an ethic of business self-interest/consumer self-reliance that favours the freedom of businesses and trusts the protection of consumers with their self-reliance on transparent information and procedures. At the other end of the spectrum there is a protective ethic or a consumer need ethic, which prioritises consumers' protection, vulnerabilities and needs. ${ }^{80}$

It can be suggested that since the enactment of the Consumer Credit Act 1974, which abandoned the statutory ceiling of interest rate, up until 2014 the regulatory vision of consumer protection was primarily influenced by a business self-interest/consumer self-reliance ethic. This meant continuous regulatory rejection to interfere in the price of credit, more specifically HCSTC, and complete reliance on accessible and transparent information as a means to protect HCSTC consumers. ${ }^{81}$ This approach has proved ineffective especially in the context of HCSTC, for a number of reasons. First, the vulnerabilities associated with HCSTC consumers make them 'completely price insensitive' and any information given would have little impact on their decision. ${ }^{82}$ Secondly, it is well established in behavioural economics that self-serving interpretation and a sense of false optimism tend to cloud consumers' judgements, ${ }^{83}$ and the vulnerabilities of HCSTC consumers would increase these risks. Finally, understanding and processing the provided information requires a certain level of education, associated with a privileged socio-economic class, that the majority of HCSTC consumers lack. ${ }^{84}$ Therefore, the regulator has shifted its vision of consumer protection towards one that is influenced by a more protective or consumer need ethical framework. This can be seen post-2014 with the imposed restrictions on certain aspects of HCSTC business conduct and the control of credit cost. However, as demonstrated above, there remain some challenges that the current regulatory provisions are not able to address, accordingly, some further measures are still needed. In this respect, it is suggested that such measures should be in line with the key features of the regulatory shift towards a more protective ethical framework and its manifestation in the regulatory provisions post-2014.

On the one hand, preventive and low-cost features are key, hence developing general clauses to address the identified challenges is not the solution. This is because these clauses are not preventive in nature and so any disputes that arise will have to be litigated before the court, which would also be costly to HCSTC consumers. Further, there is always the risk that the court's approach to interpreting these clauses may be influenced by a business self-interest/consumer self-reliance ethic. ${ }^{85}$ On the other hand, despite the clear shift in the regulatory vision of consumers' protection towards an ethical framework based more on consumer need, the regulatory approach remains not 'strongly paternalistic' as will be explained below. It is important to note that these proposed behavioural-based regulatory interventions have a complementary role to play and they are not intended to replace the substantive regulatory provisions.

\section{The theoretical case for 'libertarian paternalism'}

In order to ensure the functioning of any free market economy the regulator is still expected to protect consumers and ensure the fairness of the market. The main regulatory predicament in this respect is the extent of the regulatory involvement in the market in order to protect consumers, but without

\footnotetext{
${ }^{80}$ Ibid, at $185-87$.

${ }^{81}$ For more details see AK Aldohni 'Loan sharks v short-term lenders: how do the law and regulators draw the line?' (2013) 40(3) Journal of Law and Society 432.

${ }^{82}$ OFT 'Annexe B - price controls: evidence and arguments surrounding price control and interest rate caps for high-cost credit' evidence submitted by Gibbons, Director of Centre for Responsible Credit cited at p 50: https://webarchive.nationalarchives.gov.uk/20140402161801/http://oft.gov.uk/shared_oft/reports/consumer_credit/High-cost-credit-review/OFT1232b. pdf (last accessed 14 June 2021).

${ }^{83} \mathrm{G}$ Howells 'The potential and limits of consumer empowerment by information' (2005) 32(3) Journal of Law and Society $359-60$.

${ }^{84}$ Ibid, at 357.

${ }^{85} \mathrm{C}$ Willett 'General clause and the competing ethics of European consumer law in the UK' (2012) 71(2) Cambridge Law Journal 412.
} 
depriving them of their liberty to choose. This difficult balance has always been a point of contention between paternalists and libertarians.

On the one hand, the former's primary thesis justifies restricting individuals' liberty in order to protect their own good and welfare. ${ }^{86}$ It must be noted that in imposing any paternalistic restrictions there are a range of variables that should be taken into account. These include the voluntary nature of the choice in question, the level of rationality and information used in making this choice, the seriousness of the harm caused by the choice and its occurrence probability, the effectiveness of the restriction in preventing the harm and its level of interference in an individual's liberty. ${ }^{87}$ On the other hand, libertarians profusely reject the primary foundation of paternalism. John Stuart Mill, in his seminal book On Liberty, stated: 'That the only purpose for which power can be rightfully exercised over any member of a civilized community, against his will is to prevent harm to others. His own good, either physical or moral, is not a sufficient warrant. ${ }^{88}$ In simple terms, individuals should be free to pursue their own good in their own way even if this means making decisions that are not always serving their own best interest. ${ }^{89}$

It can be argued that, in the context of HCSTC, this is a difficult balance to strike and the regulator seems to lean towards the libertarian approach. As discussed above, all the regulatory changes brought about by the FCA were designed to restrict the HCSTC providers' liberty where they proved to harm others (ie their consumers). For instance, the regulatory restriction imposed on the number of debt rollovers and the capping of the credit cost are measures designed to prevent HCSTC providers from abusing their clients, while none of the currently applied measures interfere with the HCSTC consumers' freedom to use this type of credit.

However, in light of the earlier highlighted concerns, including the increase of HCSTC use, increase in over-indebtedness among HCSTC users, the low levels of confidence in money management and financial knowledge among HCSTC users, the evolution of HCSTC products, its online offering and the change in the demographic and socio-economic profile of its users, there is a strong argument that the regulator ought to reconsider its regulatory approach. ${ }^{90}$

This not to say that the regulator should use a 'strong paternalistic' approach, which justifies taking regulatory measures that protect those consumers against their will from the harms associated with their 'voluntary' choice to use HCSTC, ${ }^{91}$ for instance, preventing certain age groups from using HCSTC, restricting the hours during which online HCSTC providers can be accessed, or restricting its use to certain reasons. Such an approach would best be reserved as a last resort given the difficulties justifying this level of intervention in a free market economy.

Rather, it is argued that the regulatory response to the challenges identified above should be effective, innovative and at low cost to HCSTC consumers. In this regard, Sunstein and Thaler have proposed a regulatory approach which they describe as 'libertarian paternalism' and they particularly argue its importance in the context of consumer protection and welfare. From the outset they contend that their theory of 'libertarian paternalism' is not an oxymoron. The justification for this argument is that the type of paternalistic intervention used is 'relatively nonintrusive. ${ }^{92}$ This means that the

\footnotetext{
${ }^{86} \mathrm{RJ}$ Arneson 'Mill versus paternalism' (1980) 90(4) Ethics 471.

${ }^{87}$ E Zamir 'The efficiency of paternalism' (1998) 84(2) Virginia Law Review 236. Joel Feinberg discussed, in his seminal article 'Legal paternalism', certain considerations when it comes to using legal paternalism, where he paid a particular attention to the issue of non-voluntary harm, whereby state intervention can be justified to prevent the harm or at least decide whether it was voluntary or non-voluntary: see J Feinberg 'Legal paternalism' (1971) 1(1) Canadian Journal of Philosophy 105 at 113.

${ }^{88}$ JS Mill On Liberty (edited with an introduction by Gertrude Himmelfarb) (Pelican, 1976) p 68.

${ }^{89}$ Ibid, p 72.

${ }^{90}$ For broad discussion of household debt and the need to reconsider the regulatory approach to consumer credit protection in general see J Zinman 'Household debt: facts, puzzles, theories, and policies' National Bureau of Economic Research, Working Paper 20496 (September 2014).

${ }^{91}$ Feinberg, above n 87.

${ }^{92} \mathrm{C}$ Sunstein and R Thaler 'Libertarian paternalism is not an oxymoron' (2003) 70(4) The University of Chicago Law Review 1162.
} 
freedom to choose is not overridden by the intervention; rather it is influenced in a way that prompts individuals to choose better for themselves. ${ }^{93}$ Sunstein and Thaler call this nonintrusive intervention a 'nudge' and define it as 'any aspect of the choice architecture that alters people's behaviour in a predictable way without forbidding any options or significantly changing their economic incentives. To count as a mere nudge, the intervention must be easy and cheap to avoid'. ${ }^{94}$

The concept of the nudge is enshrined in behavioural science, where it has been established that individuals have certain biases affecting the way they make their decisions and that the presentation of the information in certain ways also has an impact on their final decision. ${ }^{95}$ Therefore, given the inevitability of choice architecture, a nudge could be a powerful tool to steer individuals' decisions in the right direction. ${ }^{96}$

Accordingly, it is argued that in principle libertarian paternalism is a suitable means to enhance the protection of HCSTC consumers. As it does not require any further regulatory restrictions on HCSTC providers, it would only require the inclusion of a nudge, which can be simple or take a more complex structure, that steers the consumers in the right direction or at least help them avoid making the wrong choice, which speaks volumes for their preventive nature.

It must be noted that the FCA in its October 2013 consultation referred to the need to conduct more behavioural research into ways to 'nudge' credit consumers to make better choices. ${ }^{97}$ Since then the FCA has published a number of papers exploring the use of behavioural economics by the $\mathrm{FCA},{ }^{98}$ the most recent of which explored the use of nudges regarding credit card debt with 'the semblance of success'. ${ }^{99}$

The following part of the paper evaluates the effectiveness of libertarian paternalism in the context of HCSTC. The analysis is based on a bespoke experimental survey conducted in collaboration with Citizens Advice in the North East of England where certain behavioural interventions where examined.

\section{Evaluating the effectiveness of 'libertarian paternalism'-based regulatory provisions in the context of HCSTC}

The limited access to consumer credit in the UK market, since 2008 financial crisis, has been associated with a prolific growth in the number of HCSTC providers. The Government response has been to impose regulatory changes to address areas of perceived problematic business practice (eg affordability checks and cap on cost of credit). While regulatory reforms have a role to play in protecting HCSTC consumers, little attention has been directed to examining ways in which consumers' attitudes to HCSTC might be changed. Consuming today while borrowing against the future (hence accessing credit) is a manifestation of impatience, against which individuals need to sometimes exert self-control. Economic theory suggests, however, that individuals may fail to learn to exert full control over their behavioural biases. ${ }^{100}$ Hence, the behavioural economics literature has turned to

\footnotetext{
${ }^{93} \mathrm{C}$ Sunstein Why Nudge: The Politics of Libertarian Paternalism (Yale University Press, 2014) p 54 and see C Sunstein and $\mathrm{R}$ Thaler Nudge, Improving Decisions about Health, Wealth and Happiness (Penguin, 2008) p 5.

${ }^{94}$ Sunstein and Thaler, above n 93, p 6.

${ }^{95}$ Sunstein and Thaler, above n 92. See also Sunstein and Thaler, above n 93, pp 21-78.

${ }^{96}$ Sunstein, above n 93, pp 17, 118-22.

${ }^{97}$ FCA Detailed Proposal for the FCA Regime for Consumer Credit CP 13/10 (October 2013) p 78, https://www.fca.org.uk/ your-fca/documents/consultation-papers/cp13-10 (last accessed 14 June 2021).

${ }^{98}$ For example see K Erta et al 'Applying behavioural economics at the Financial Conduct Authority' Occasional Paper No 1 (FCA, April 2013) and Financial Advice Working Group for HM Treasury and the Financial Conduct Authority 'Rules of thumb and nudges: improving the financial wellbeing of UK consumers' (FCA, March 2017); P Adams and L Smart 'From advert to action: behavioural insights into the advertising of financial products' Occasional Paper No 26 (April 2017).

${ }^{99} \mathrm{P}$ Adams et al 'The semblance of success in nudging consumers to pay down credit card debt' Occasional Paper No 45 (FCA, July 2018).

${ }^{100}$ S Nageeb Ali 'Learning self-control' (2011) 126(2) The Quarterly Journal of Economics 857; and J Schwartzstein 'Selective attention and learning' (2014) 12(6) Journal of the European Economic Association 1423.
} 
examining the success of commitment mechanisms as a form of self-control to tie individuals to their original intentions to save. ${ }^{101}$ Such commitment devices are difficult to legislate for in a regulatory framework, hence we evaluate here the extent to which a simple nudge versus a more complex behavioural intervention might change consumer attitudes and, therefore, by association, their tendency to use HCSTC.

\section{(a) Behavioural interventions: the influence of related literature on the survey design}

The provision of financial information in credit decisions has been examined in the context of credit card repayment decisions. For example, the research in the US of Jones et al examines the impact of regulatory change in the context of billing disclosure changes mandated by the Credit Card Accountability Responsibility and Disclosure (CARD) Act and finds evidence of an increase in the amounts of credit card debt paid off each month. Thus, this documents the ability of behaviourally targeted improvements in information disclosures to impact positively on consumer behaviours. ${ }^{102}$ Related, Stewart reports a strong and causal relationship between minimum repayment size and actual repayment behaviour, demonstrating that minimum repayments act as psychological anchors, ${ }^{103}$ while McHugh and Ranyard find that individuals repay significantly more when information concerning the long-term consequences of repayment options (ie associated total cost and loan duration) is provided. ${ }^{104}$ In the case of HCSTC, such costs are explicit in the case of total cost and duration and of little relevance in the case of minimum repayment size.

There is clear evidence from behavioural economics/finance that even small interventions can have large and positive effects on behaviour, for instance in the context of saving behaviour, ${ }^{105}$ and in the context of overdraft fees. ${ }^{106}$ Hence, in the survey we examine the influence of a simple behavioural intervention (simple nudge) intended to draw attention to the costs associated with HCSTC. To this end, we ask respondents to list their recent experience of using HCSTC.

While small interventions, or simple nudges, have been seen to have positive effects on individual behaviour, the repeated use of HCSTC arrangements by some sections of society ${ }^{107}$ suggest that small interventions may not be sufficient to shift behaviour. Indeed, contrary to their main results, Jones et al find minimal evidence of repayment behaviour changes in response to the CARD Act (discussed above) among those households continuing to carry credit card debt (ie credit revolvers). ${ }^{108}$

Further, using a randomised field experiment at payday stores and drawing on behavioural insights from psychology and economics to inform treatment design, Bertrand and Morse investigate whether ways to present information about the costs of payday loans might impact decisions to continue to use payday lenders. They find that information disclosure intended to make people think less narrowly and to consider how costs accumulate over time reduces borrowing by $11 \%$ relative to a control group. Bertrand and Morse note, however, that despite the success of their relatively low-cost intervention policy, they remain doubtful as to the sufficiency of information disclosure as a remedy to

\footnotetext{
${ }^{101} \mathrm{R}$ Thaler and S Benartzi 'Save more tomorrow ${ }^{\mathrm{TM}}$ : using behavioral economics to increase employee saving' (2004) 112 (S1) Journal of Political Economy S164.

${ }^{102} \mathrm{LE}$ Jones et al 'Effects of informational nudges on consumer debt repayment behaviors' (2015) 51 Journal of Economic Psychology 16.

${ }^{103} \mathrm{~N}$ Stewart 'The cost of anchoring on credit-card minimum repayments' (2009) 20(1) Psychological Science 39.

${ }^{104} \mathrm{~S} \mathrm{McHugh}$ and R Ranyard 'Credit repayment decisions: the role of long-term consequence information, economic and psychological factors' (2012) 4(2) Review of Behavioural Finance 98.

${ }^{105} \mathrm{JJ}$ Choi 'Small cues change savings choices' (2017)142 Journal of Economic Behavior \& Organization 378.

${ }^{106} \mathrm{~V}$ Stango and J Zinman 'Limited and varying consumer attention: evidence from shocks to the salience of bank overdraft fees' (2014) 27(4) The Review of Financial Studies 990.

${ }^{107}$ The average number of HCSTC loans taken by consumers in 2016 was just under five where $60 \%$ of HCSTC consumers took out three or fewer and $10 \%$ took out 12 or more. See FCA 'High-cost credit: including review of the high-cost short-term credit price cap' (FS17/19) 14; and see also FCA 'High-cost credit review technical annex 1: credit reference agency (CRA) data analysis of UK personal debt' (July 2017) table 5, 22.

${ }^{108}$ Jones et al, above n 102 , at $16-33$.
} 
payday borrowing. ${ }^{109}$ Such a view is further strengthened by Bhattacharya et al who find, in the context of stock investing, that individuals fail to follow unbiased financial advice to the detriment of their own financial wellbeing. ${ }^{110}$

We conclude from the above that individuals' financial decisions, including those in the context of HCSTC, are difficult to change. Merely providing individuals with information (disclosure) about the exorbitant costs associated with HCSTC, ${ }^{111}$ even in behaviourally informed ways designed to draw attention to such costs, may not be sufficient to invoke such change. Even offering unbiased financial advice might not affect a desired reduction in the use of HCSTC. Consequently, via a more complex behavioural intervention, we examine how making salient the temporal trade-off between current consumption on credit and forgone future opportunities, focusing on bringing to mind such opportunity costs and how individuals think about these, might be used to change attitudes to the use of HCSTC. To this end, we draw on two insightful theories from psychology that suggest ways in which the temporal trade-off between current and future consumption might be portrayed: construal level theory and regulatory focus.

\section{(b) Experimental survey design and data collection}

While the general population's attitudes to HCSTC are of interest, it is clearly informative to capture the attitudes of consumers of HCSTC ( population of interest) and to examine ways in which their attitudes might be influenced. To this end, we design and administer a bespoke questionnaire in conjunction with the Newcastle-upon-Tyne branch of Citizens Advice (CA) thus accessing their client-base of users of HCSTC. The socio-economic and demographic make-up of the North East make Newcastle an ideal location to administer the survey. The North East has the second highest loans per capita ratio in the UK (118 per 1000), second only to the North West (125 per 1000). ${ }^{112}$ Figure $1^{113}$ shows that the North East, as a region, leads the UK in the use of payday loans, with the highest number of unique clients per head of regional population $(0.071 \%)$, followed by Wales $(0.051 \%)$ and the West Midlands $(0.045 \%)$.

As the largest of the cities in the North East, Newcastle represents an excellent test bed in which to examine the extent to which attitudes to the use of HCSTC might be changed by behavioural interventions.

Attendees at the Newcastle CA branch were approached by CA staff and asked to complete the survey in person while at the branch. The questionnaires elicit individuals' attitudes to and experiences of HCSTC (eg purpose of credit, essential versus non-essential), along with a range of relevant demographics (eg age, gender, marital status, dependents, income, etc). Interventions are modified and randomly distributed across respondents in an experimental design intended to examine the impact on attitudes of a simple nudge and of more complex behavioural interventions. In the case of the latter, treatment groups are included manipulating opportunity cost along the dimensions of construal level theory (abstract versus concrete) and regulatory focus (promotion versus prevention), along with a control sample not exposed to an intervention. Attitudes are a key factor in observed behaviour, ${ }^{114}$

\footnotetext{
${ }^{109} \mathrm{M}$ Bertrand and A Morse 'Information disclosure, cognitive biases, and payday borrowing' (2011) 66(6) The Journal of Finance 1865 .

${ }^{110} \mathrm{U}$ Bhattacharya et al 'Is unbiased financial advice to retail investors sufficient? Answers from a large field study' (2012) 25(4) The Review of Financial Studies 975.

${ }^{111} \mathrm{R}$ Mann 'Assessing the optimism of payday loan borrowers' (2013) 21(1) Supreme Court Economic Review 105. Indeed, evidence in Mann that payday borrowers are unbiased in their forecasts of how long it will take them to repay their loans suggests that information generally, or concerning costs specifically, might not be lacking.

${ }^{112}$ Financial Conduct Authority 'Consumer credit - high-cost short-term credit lending data' https://www.fca.org.uk/data/ consumer-credit-high-cost-short-term-credit-lending-data-jan-2019 (last accessed 14 June 2021).

${ }^{113}$ Data source: Newcastle-upon-Tyne Citizens Advice (CA) for the period 2014-17. Data provided to the authors by CA Newcastle in an email which is kept on file with authors.

${ }^{114}$ I Ajzen 'The theory of planned behavior' (1991) 50(2) Organizational Behavior and Human Decision Processes 179.
} 


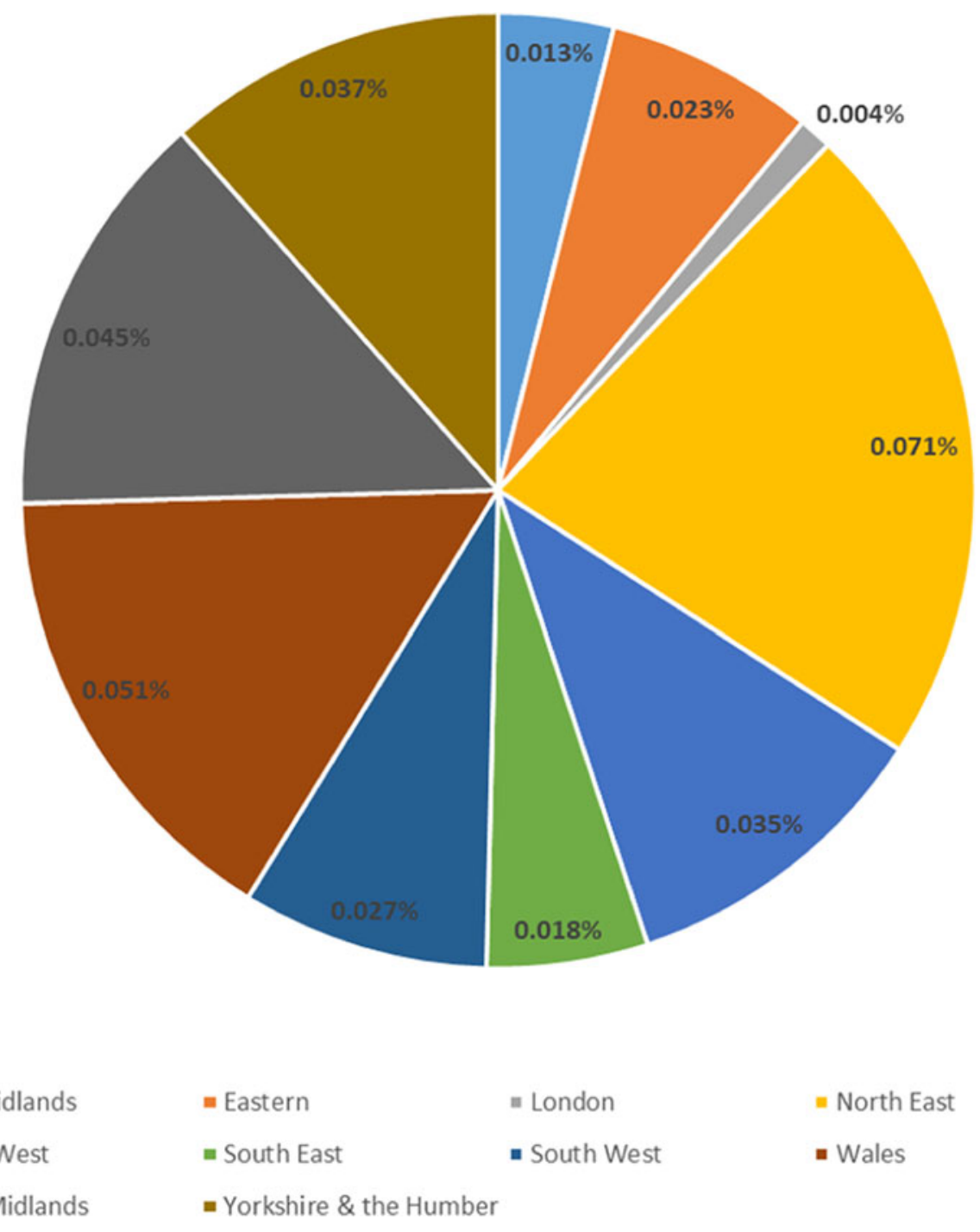

Figure 1. Number of unique payday loan clients as percentage of regional population

hence we expect that evidence of changes in attitude as a result of the nudge/interventions we investigate will likely feed into changes in behaviour, thus impacting on the use of HCSTC.

\section{(i) Behavioural scenario: simple nudge}

We ask respondents in our behavioural survey to imagine themselves in a scenario whereby they are looking to borrow money for a short duration and ask them to respond as honestly as possible. We mock up a fictional lender, 'cash2pocket.co.uk', and respondents read the information below (see Figure 2), as would be provided by a lender in an online application form.

We ask all respondents to indicate whether they have used a payday lender before and ask those respondents in the simple nudge condition to list their prior experiences of using HCSTC including the amount borrowed, the number of times rolled over and the total amount eventually repaid. Bringing this information to mind makes it salient to respondents in the simple nudge condition. A control sample of respondents are asked only to indicate if they have used a payday lender before 


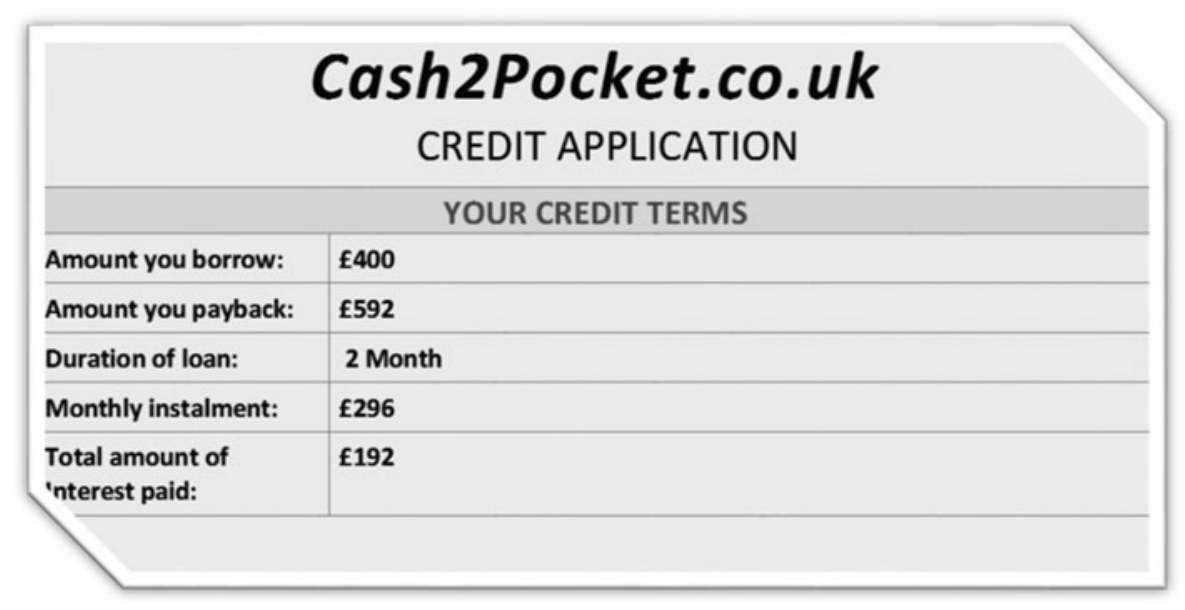

Figure 2. Stylistic representation of a HCSTC application

and so are not exposed to the simple nudge. We then ask all respondents, in both the nudge and no-nudge conditions, 'After reading the information on the cash2pocket.co.uk website, how likely would you be to borrow the money?', with responses on a 7 -point Likert scale ranging from $1=$ 'not at all' to $7=$ 'certain'. Comparison of responses across the nudge and no-nudge versions of the survey allows us to examine the influence of the simple nudge of bringing to mind prior experiences of using HCSTC on individuals' attitudes towards HCSTC.

\section{(ii) Behavioural scenario: complex behavioural intervention}

Liberman and Trope's construal level theory distinguishes between objects or events that are perceived as temporally proximate (ie close in time) and those that are distant (farther away in time), with the former construed on a concrete, contextual level (ie focusing narrowly on specifics and details), while the latter are construed on an abstract, schematic level (ie looking at the bigger picture, rather than details). ${ }^{115}$ Relative to a concrete construal (with the emphasis on 'how' to achieve one's objectives), evidence suggests that an abstract construal (with the emphasis on 'why' objectives are important) promotes self-control and inhibits temptation, thus increasing the desirability of larger rewards in the future than smaller rewards now. Evoking an abstract construal has been associated with the pursuit of future benefits rather than immediate needs. Perhaps counterintuitively, therefore, interventions designed to evoke abstract thinking of the associated opportunity costs of credit may be expected to reduce the attraction of HCSTC, relative to concrete thinking. Hence, bigger picture thinking about the future opportunities forgone as a consequence of funding consumption today via credit, rather than focusing on the details and specifics of the opportunity costs, might be expected to make HCSTC less attractive.

The principle of Higgins' regulatory focus distinguishes between two strategies for goal attainment: promotion focus and prevention focus. Within a promotion focus, attention is directed at the attainment of positive outcomes, whereas attention is directed at the avoidance of negative outcomes within a prevention focus. ${ }^{116}$ Pennington and Roese link regulatory focus and temporal distance, suggesting that temporal distance to a goal influences the extent to which evaluations are framed in terms of promotion or prevention focus. Temporally distant goals are associated more with promotion than

\footnotetext{
${ }^{115} \mathrm{~N}$ Liberman and Y Trope 'The role of feasibility and desirability considerations in near and distant future decisions: a test of temporal construal theory' (1998) 75(1) Journal of Personality and Social Psychology 5.

${ }^{116}$ E Tory Higgins 'Promotion and prevention: regulatory focus as a motivational principle' (1998) 30 Advances in Experimental Social Psychologyl.
} 
prevention, while temporally proximate goals are associated more with prevention than promotion. In this latter case, prevention exerts a greater influence on self-regulation as events become closer in time. ${ }^{117}$ Pennington and Roese hypothesise that inducing a promotion rather than prevention focus (with attention directed toward the attainment of positive outcomes rather than the avoidance of negative ones), would lead an individual to devote increased consideration to a temporally distant event. ${ }^{118}$ Interventions designed, therefore, to encourage a promotion focus may cause an individual to give increased consideration to the temporally distant opportunity costs of credit and so may be expected to reduce the attraction of HCSTC, relative to a prevention focus. Hence, focusing on obtaining positive outcomes associated with future opportunities forgone as a consequence of funding consumption today via credit, rather than focusing on avoiding negative outcomes associated with the same opportunity costs, might be expected to make HCSTC less attractive.

We employ a 2 × 2 within-subject experimental design with construal level (abstract versus concrete) and regulatory focus (promotion versus prevention), thus allowing both main effects and the interaction to be examined without confounding effects. The behavioural scenario as presented to respondents is outlined in Exhibit 1.

Exhibit 1: Behavioural scenario for complex intervention (italics added)

Please imagine yourself in the following situation and respond as honestly as possible.

You have been trying to put a little money aside to save up enough to pay for your ideal new smartphone. You expect to have enough money saved in around 6 months' time.

$<\{$ abstract $\}$ [concrete] intervention inserted here $>$

In the meantime, you have been invited on a stag/hen weekend away, but do not have enough money to go. You are considering taking out a short-term loan to be able to afford the weekend. You are looking to borrow $£ 450$ for a period of three months. The following credit agreement is drawn up by the provider of funds.

You borrow $£ 450$ for 3 months at the start of next month. Your total repayment amount over 3 months will be $£ 669.39$ paid over 3 equal instalments of $£ 223.13$ on the last day of each month. The total charge for credit is $£ 219.40$.

Card Verification: $£ 0$ and maximum arrears fee per loan is capped at $£ 15$.

APR per $£ 450$ loan is $1116 \%$. Per annum interest rate is $277.40 \%$ and the effective loan interest is $48.76 \%$.

The likely effect of borrowing the money and going on the stag/hen weekend away is that you will have to wait longer to buy your ideal smartphone. You estimate that it might take another 6 months, in addition to your original estimate of 6 months, to save up the money you need.

$<\{$ promotion $\}$ [prevention] intervention inserted here $>$

Respondents were then asked 'Thinking about the above, how likely would you be to borrow the money?', with responses on a 7 -point Likert scale ranging from $1=$ 'not at all' to $7=$ 'certain'. In the \{abstract\} [concrete] versions of the intervention respondents were instructed to (emphasis in original):

Think of $\{$ why\} $[$ how $]$ you are saving this money and briefly list below things that come to mind.

${ }^{117}$ GL Pennington and NJ Roese 'Regulatory focus and temporal distance' (2003) 39(6) Journal of Experimental Social Psychology 563.

${ }^{118}$ Ibid. 
In the \{promotion\} [prevention] versions of the intervention we directed respondents to think about [attainment of a positive outcome\} [avoidance of a negative outcome] (emphasis in original):

If you decide not to borrow the money you will \{be able to enjoy your new smartphone as planned in 6 months time [avoid having to delay buying your new smartphone by an additional 6 months].

Given the within-subject nature of the experimental design, respondents were randomly presented with a mocked-up HCSTC agreement as outlined in Exhibit 1, comprising one of the construal level conditions and one of the regulatory focus conditions. Respondents in the abstract construal condition were asked to think about why they are saving money, thus promoting a broader big picture perspective when it comes to thinking about the future opportunities foregone as a consequence of funding consumption today via credit, while those in the concrete construal condition were asked to think about how they would be saving money, thus promoting a narrower focus on contextual specifics and details. Turning to regulatory focus, if they did not go ahead with the HCSTC agreement, respondents in the promotion condition would be able to enjoy the new smartphone in six months as planned (ie promotion of a positive outcome), while those in the prevention condition would avoid a further delay of six months in buying the new smartphone (ie prevention of a negative outcome). The opportunity cost of using the HCSTC, the additional six-month delay before sufficient money is saved to buy the smartphone, is present and salient in all versions of the behavioural interventions. We also employ a control group not exposed to a behavioural intervention, but for whom the opportunity cost of the HCSTC is salient

The manipulation of temporal construal, specifically the degree to which future consequences are seen as proximal or distant, has been shown to impact on attitudes and behaviours across a range of domains, including crime/wrongdoing ${ }^{119}$ and climate change. ${ }^{120}$ We are confident, therefore, that the behavioural interventions we instigate via the manipulation of temporal construal, through both the construal level and the regulatory focus treatment conditions, are built on sound theoretical ground and are rooted in prior empirical evidence.

\section{(c) Results}

\section{(i) Sample statistics}

The survey was completed by 163 respondents through collaboration with the Newcastle branch of the CA. Of the 163 respondents, there were 90 males and 68 females (5 respondents did not indicate gender) with average ages of 43 and 39 years, respectively. Good representation in lower age bands was achieved with $35 \%$ and $47 \%$ of males and females, respectively, across the 18-24 and 25-34 year-old bands. The majority of respondents, 114 (69.9\%), were users of HCSTC, with 72\% of males and $68 \%$ of females in this category. Administering the survey through the Newcastle branch of the CA had the desired effect of oversampling users of HCSTC relative to the UK population where only $0.028 \%{ }^{121}$ are users of payday loans. Of the 114 users of HCSTC, $17.1 \%, 21.6 \%, 18.9 \%, 16.2 \%, 18.0 \%, 5.4 \%$, $2.7 \%$ and $0 \%$, respectively, were from the $18-24,25-34,35-44,45-54,55-64,65-74,75-84$ and $85+$ age categories ${ }^{122}$ (with three respondents not reporting age). Our sample demographics compare favourably with those reported in Figure 3 below for the UK as a whole. ${ }^{123}$

Figure 4 shows the frequency of use of HCSTC split by gender. As can be seen, while the percentage of HCSTC users declines for both males and females as the frequency of use increases, there remains a

\footnotetext{
${ }^{119} \mathrm{~J}$ Peetz et al 'Temporal distancing and defensiveness in the face of past in-group wrongdoing' (2010) 36 Personality and Social Psychology Bulletin 598.

${ }^{120} \mathrm{M}$ Soliman et al 'Wrinkles in time and drops in the bucket: circumventing temporal and social barriers to pro-environmental behavior' (2018) 8(2) SAGE Open, 1-10.

${ }^{121}$ Data source: as per $\mathrm{n} 100$. CA report a total of 15,762 unique payday loan clients from a UK population of $56,075,456$ $(0.028 \%)$. Our sample of 114 users of HCSTC, therefore, represents $0.72 \%$ of all such CA clients.

${ }^{122}$ Corresponding figures for the UK as a whole from the FCA Financial Lives Survey 2017 based on a sample of 287 HCSTC users are; $16.4 \%, 33.4 \%, 20.2 \%, 17.8 \%, 9.1 \%, 2.8 \%, 0.3 \%$ and $0 \%$.

${ }^{123}$ CMA, above n 65, App 2.3, Demographics.
} 

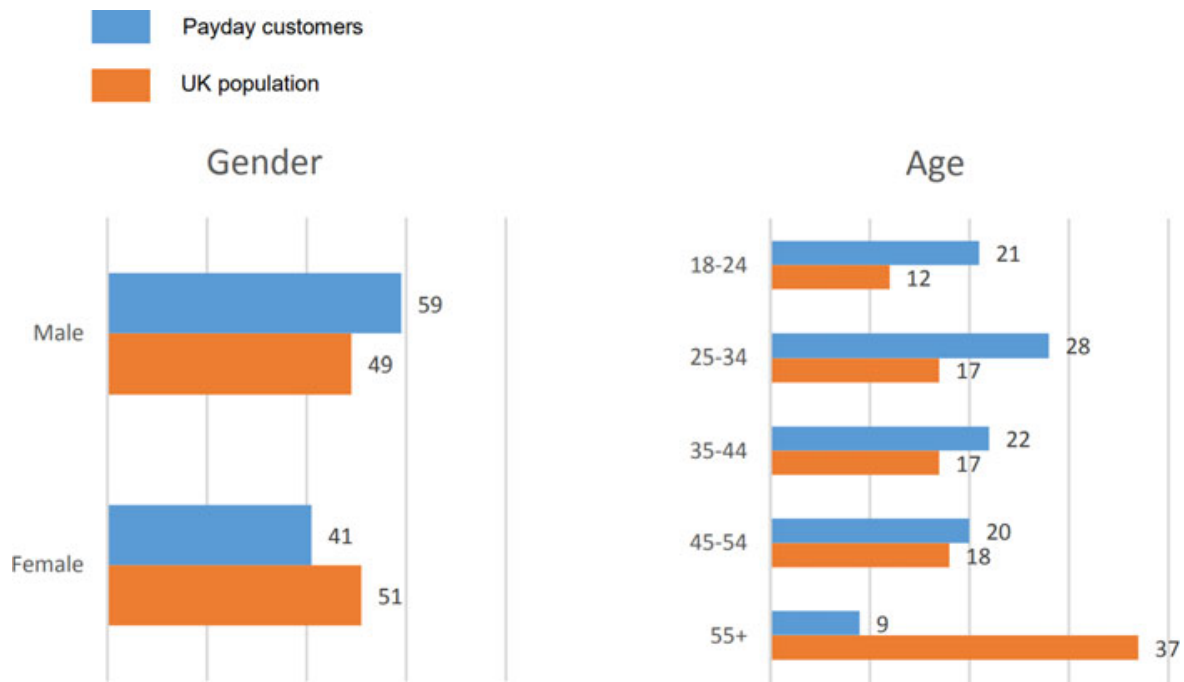

Figure 3. Gender and age characteristics of payday customers relative to UK population

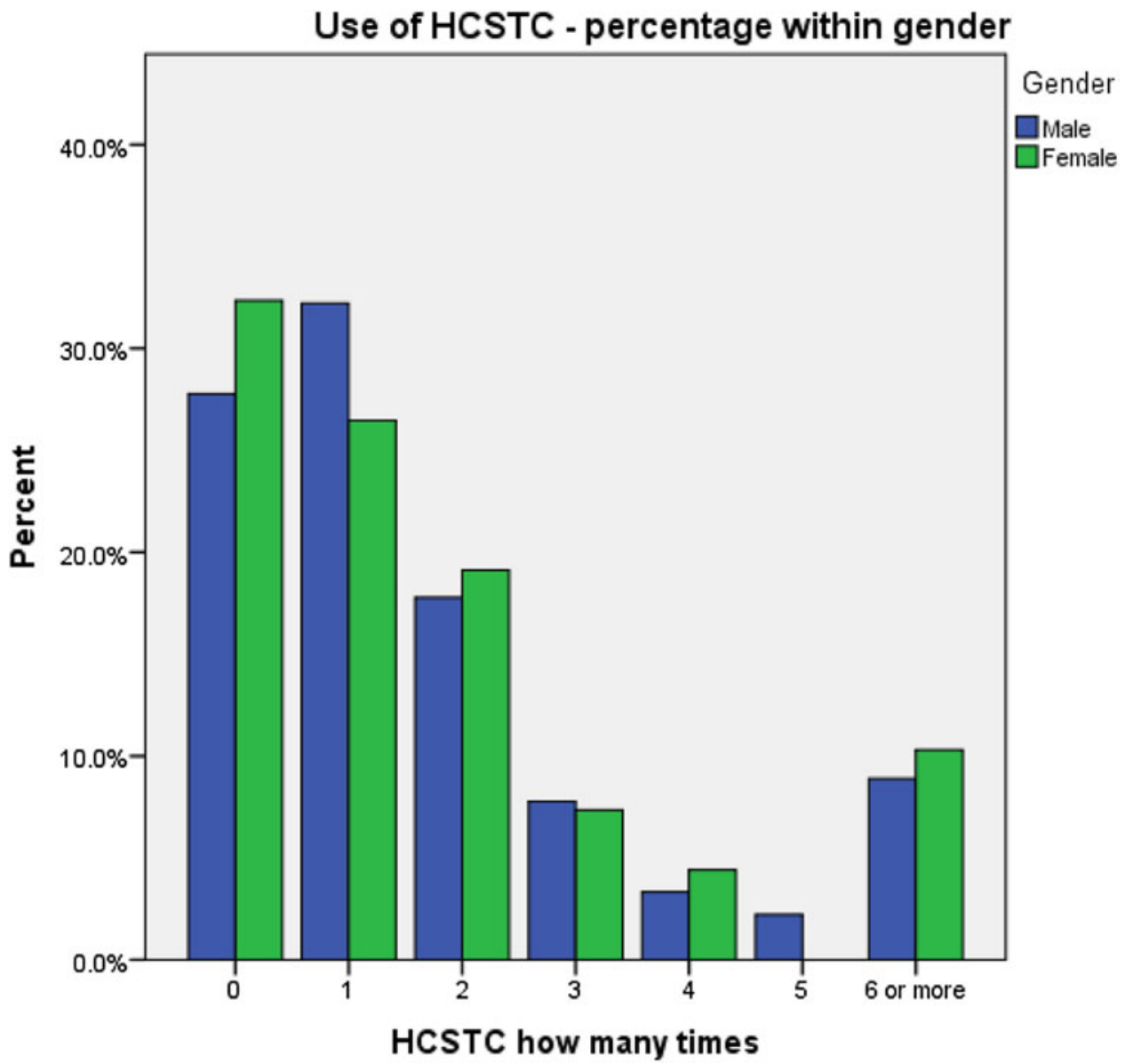

Figure 4. Frequency of HCSTC use by gender 


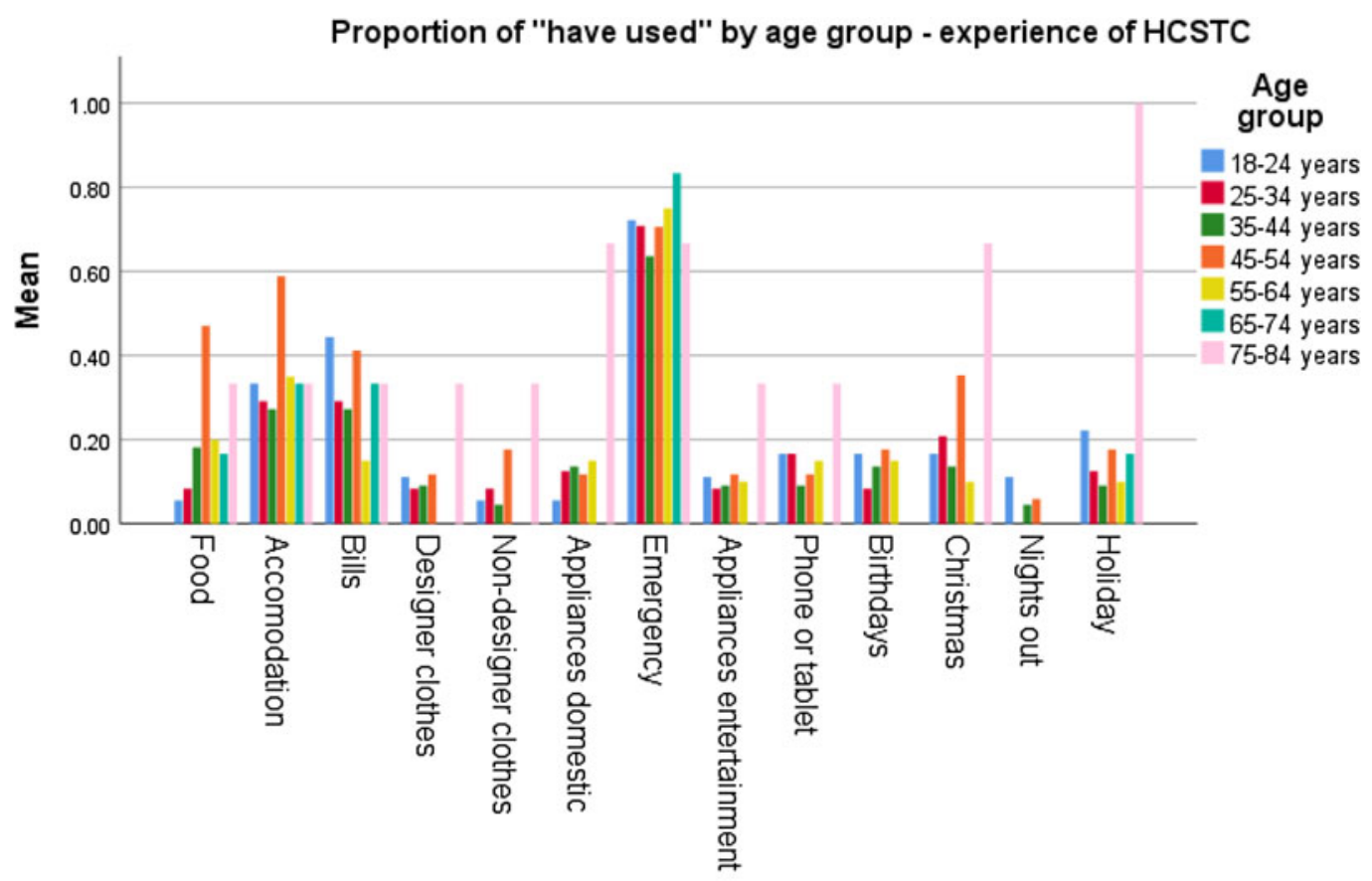

Category

Figure 5. Proportion of "Have used" by category and age group

not insignificant percentage of both males and females that make repeat use of payday loans, with $40 \%$ (9\%) of males reporting using HCSTC more than once (six or more times), while the corresponding figures for females are $41 \%$ and $10 \%$, respectively.

Respondents were asked to indicate those categories of expenditure for which they had previously used HCSTC, including food, accommodation bills, utility bills, designer clothes, non-designer clothes, domestic appliances (eg microwave, washing machine), emergency, entertainment appliances (eg TV, PS4, Xbox), mobile phone or tablet, birthdays, Christmas, night out, and holiday.

Figure 5 reports the proportion of users of HCSTC by age groups for each of the 'have used' categories. By way of contrast, Figure 6 reports the proportion of respondents by age groups for those indicating they would use HCSTC in the same categories of expenditure (ie 'would use' categories), both for users of HCSTC (Panel A) and non-users of HCSTC (Panel B). While the 'would use' responses for users of HCSTC are higher than those of non-users for all categories and for all age groups, as might be expected, perhaps more insightful is the finding that in general non-users would largely only consider using HCSTC for what might be classed as essential purchases (eg food, accommodation, bills, emergencies, etc). In contrast, and in line with conspicuous consumption discussed earlier, a significant proportion of users of HCSTC would also use it for what might be classed as non-essential purchases (eg phones, nights out and holidays, etc).

\section{(ii) Behavioural scenario: simple nudge}

A total of 93 respondents completed the simple nudge, listing their prior experiences of using HCSTC, including for each prior experience the amount borrowed, the number of times rolled over and the total amount eventually repaid, thus making salient to them the cost associated with HCSTC. A further 39 respondents (the control sample) were not exposed to the nudge. We restrict analysis to the $133^{124}$ respondents with prior experience of using HCSTC to remove the confounding effect of

\footnotetext{
${ }^{124}$ One response is omitted from the 133 users of HCSTC due to missing data.
} 


\section{Panel A}

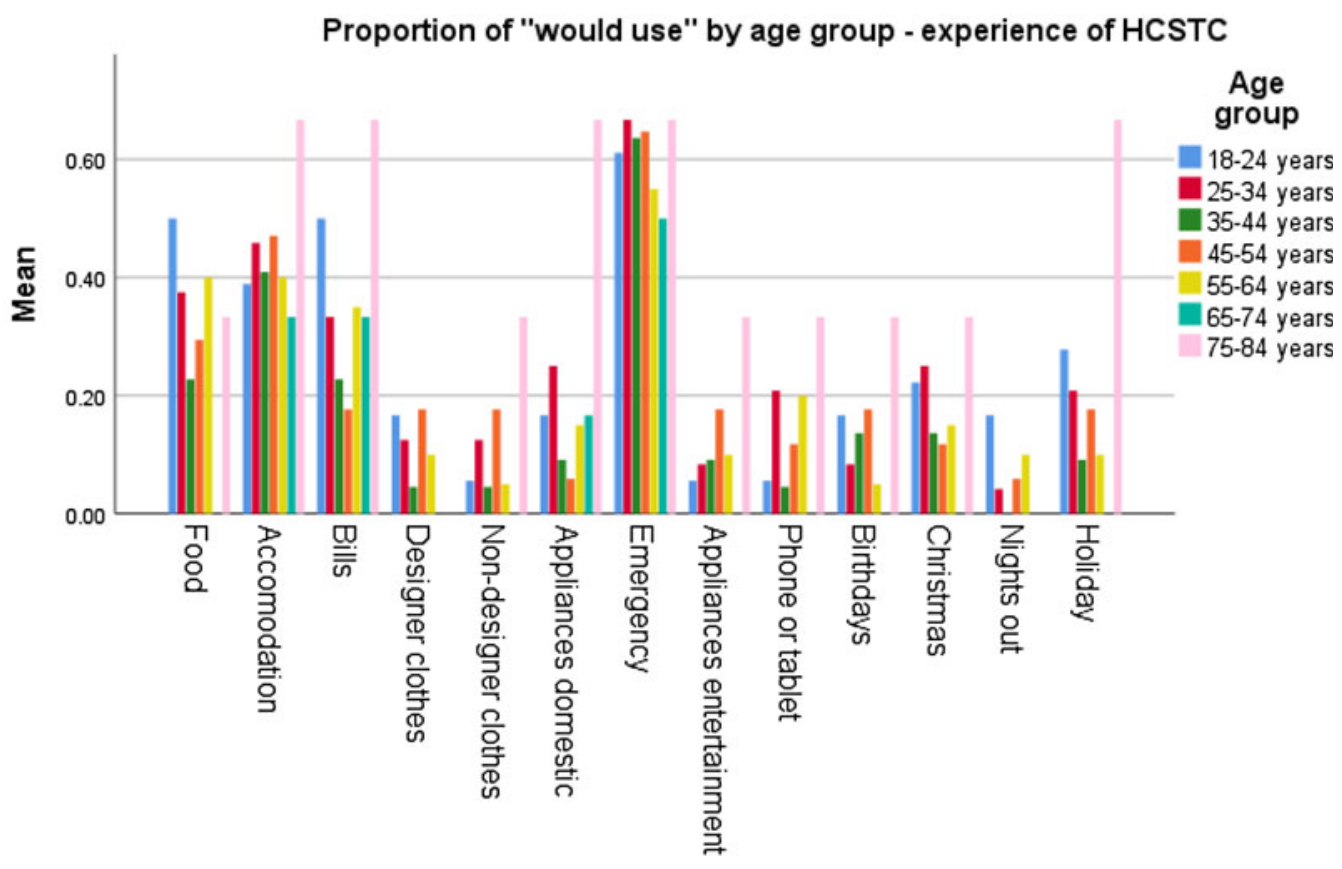

Category

Panel B

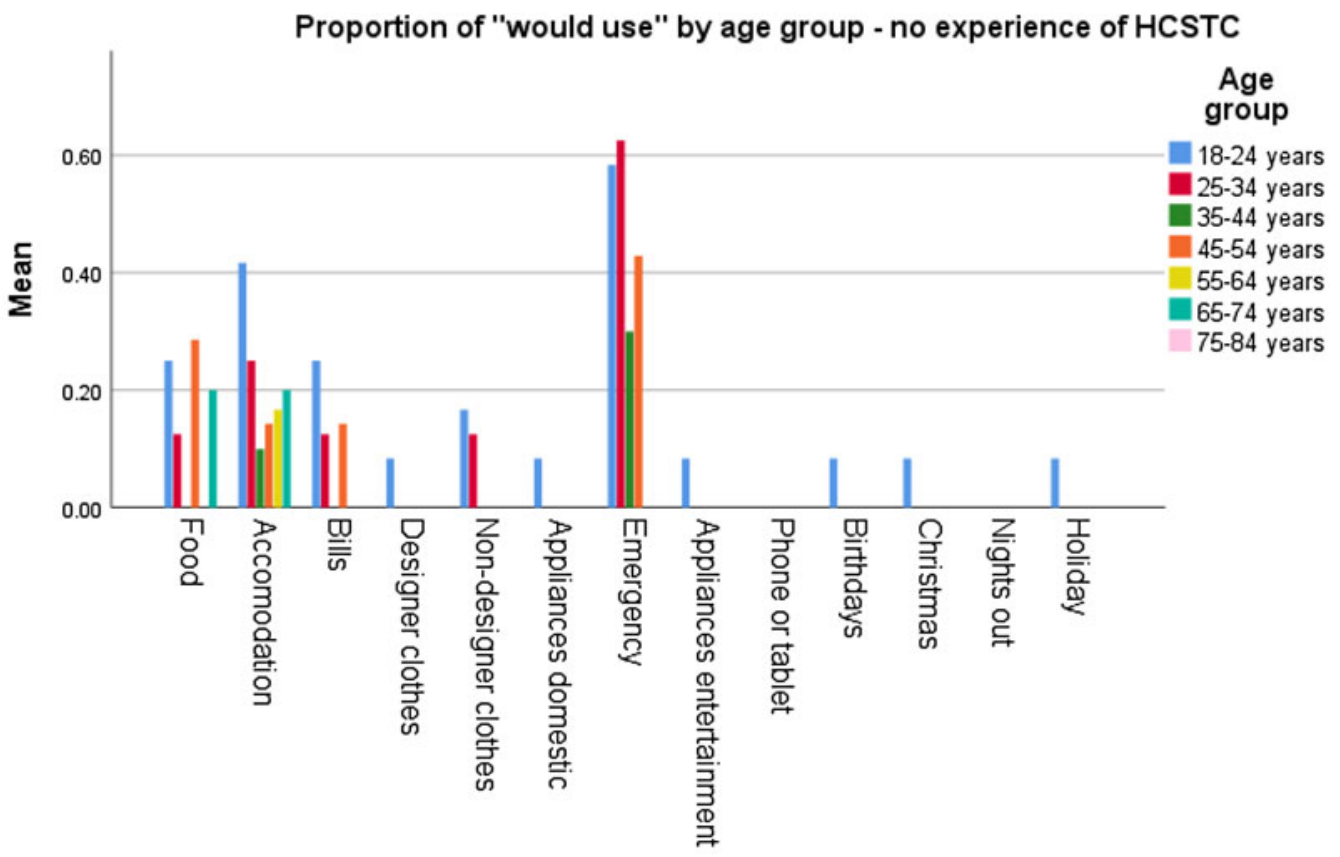

\section{Category}

Figure 6. Proportion of "Would use" by category and age group 
non-users from the control sample and to ensure we compare like with like (ie nudged users versus non-nudged users).

We asked respondents the likelihood that they would borrow the money in the cash2pocket.co.uk scenario (see Figure 2) using a 7 -point Likert scale ranging from $1=$ 'not at all likely' to $7=$ 'certain'. We find a statistically significant difference in response across the nudge and control samples (mean likelihood scores of 2.94 and 1.62, respectively, and $\mathrm{p}<0.01$ ), indicating that those users of HCSTC exposed to a simple nudge intended to impact negatively on their attitude to HCSTC in the behavioural scenario, were in fact significantly more likely to borrow the money. The result is robust to the inclusion of a range of demographic controls including age, gender, education etc.

The result supports the conclusion that a simple nudge requiring users of HCSTC to think about the costs associated with their prior use of such credit is not effective at weakening their attitudes to the continued use of HCSTC. On the contrary, a simple nudge such as this may serve to strengthen, not weaken, their attitudes. Next, we turn our attention to examine whether more complex interventions rooted in psychological theory can have the desired effect.

\section{(iii) Behavioural scenario: complex behavioural intervention}

A total of 132 respondents completed the $2 \times 2$ treatment conditions of the complex behavioural intervention, with roughly comparable numbers of respondents across the four cells (ranging from 27 to 39). We asked respondents the likelihood that they would borrow the money in the complex intervention scenario (see Exhibit 1 above) using a 7-point Likert scale ranging from $1=$ 'not at all likely' to 7 = 'certain'. Mean likelihood scores across the four treatment conditions were 2.14, 2.41, 2.62 and 2.18 for Abstract-Promotion, Abstract-Prevention, Concrete-Promotion and Concrete-Prevention, respectively. ${ }^{125}$ In initial Bonferroni-adjusted multiple pairwise comparisons, we find no statistically significant difference in responses across the four treatment conditions (with all $\mathrm{p}>0.10$ ), both including and excluding respondents with no prior experience of using HCSTC. On first examination, therefore, it might seem the behavioural interventions do not impact the mean likelihood of going ahead with the HCSTC agreement. However, such tests do not exploit the factorial nature of the experimental design nor do they incorporate the demographic data on respondents.

A two-way ANOVA, including a range of demographic controls (including gender, marital status, financial dependents, employment status, state benefits, education and income) and controls for prior experience of HCSTC (number of times used and frequency of use), provides a much clearer picture of the impact of the complex behavioural intervention. As can be seen in Table 1, while Regulatory (Promotion versus Prevention) has no main effect $(F(1,98)=0.101, p>0.10)$, Construal (Abstract versus Concrete) has a marginally significant main effect $(F(1,98)=3.600, p<0.10)$ and the Construal $\mathrm{x}$ Regulatory interaction is statistically significant $(\mathrm{F}(1,98)=4.107, \mathrm{p}<0.05)$.

To gain insight into how the interventions might impact on the likelihood to borrow and their direction of effect, we examine the estimated marginal means of the four treatment conditions and perform Bonferroni-adjusted multiple pairwise comparisons. As depicted in Table 2, we find strong evidence of a statistically significant reduction in mean likelihood scores across the concrete (2.813) versus abstract (1.882) construal levels under the promotion treatment for regulatory focus. If attention is directed towards the attainment of positive outcomes (promotion focus), when individuals are required to think about why the objective (eg saving money to buy a smartphone) is important they are less likely to borrow money via HCSTC to fund another course of action (eg to go on a stag/hen weekend) with an associated opportunity cost (eg a delay in the purchase of the smartphone) than when required to think about how the objective might be achieved. The same is not true when attention is directed towards the avoidance of negative outcomes (prevention focus). When thinking about the positives associated with obtaining the smartphone in six months as planned, individuals adopting a big picture perspective of why they are saving money (ie to buy the smartphone) are less inclined

\footnotetext{
${ }^{125} \mathrm{~A}$ control condition with no intervention on 31 respondents gave a mean likelihood to borrow score of 2.29 , in the middle of the range of scores for across the treatment conditions, as might be expected.
} 
Table 1. Analysis of the impact of Construal and Regulatory Focus on likelihood to borrow score: Two-way between subjects ANOVA

\begin{tabular}{lccccc} 
& Type III Sum of Squares & df & Mean square & F & Sig. \\
\hline Main effects & & & & & \\
\hline Construal & 4.987 & 1 & 4.987 & 3.600 & $0.061^{\star}$ \\
\hline Regulatory & 0.139 & 1 & 0.139 & 0.101 & 0.752 \\
\hline Interactions & & & & 4.107 & $0.045^{\star \star}$ \\
\hline Construal x Regulatory & 5.690 & 1 & 5.690 & & \\
\hline Controls & & & & & \\
\hline Yes & & & & & \\
\hline R-squared $=0.230$ & & & & & \\
\hline
\end{tabular}

${ }^{a}$ Covariates not reported include demographic controls (including gender, marital status, financial dependents, employment status, state benefits, education and income) and controls for experience of HCSTC (number of times used and frequency of use). Significance levels: ${ }^{\star \star \star}=0.01 ;{ }^{* \star}=0.05 ;{ }^{*}=0.10$

Table 2. Analysis of the impact of Construal and Regulatory Focus on likelihood to borrow score: Bonferroni-adjusted pairwise comparisons

\begin{tabular}{|c|c|c|c|}
\hline Treatment 1 & Treatment 2 & Estimated marginal mean ${ }^{a}$ & Sig. diff. between levels of Treatment 2 \\
\hline \multirow[t]{2}{*}{ Abstract } & Promotion & 1.882 & 0.243 \\
\hline & Prevention & 2.290 & \\
\hline \multirow[t]{2}{*}{ Concrete } & Promotion & 2.813 & $0.091^{*}$ \\
\hline & Prevention & 2.255 & \\
\hline \multirow[t]{2}{*}{ Promotion } & Abstract & 1.882 & $0.006^{\star \star \star}$ \\
\hline & Concrete & 2.813 & \\
\hline \multirow[t]{2}{*}{ Prevention } & Abstract & 2.290 & 0.919 \\
\hline & Concrete & 2.255 & \\
\hline
\end{tabular}

${ }^{a}$ Covariates appearing in the model are evaluated at the following values: Gender $=1.43$, Marital status $=1.90$, Financial dependents $=1.76$, Employment status $=3.80$, State benefits $=1.58$, Qualification $=2.47$, Net income per month $=1015.20$, HCSTC number of times $=2.82$, HCSTC frequency $=3.68$. Significance levels using Bonferroni adjustment for multiple pairwise comparisons: ${ }^{\star \star \star}=0.01 ;{ }^{\star \star}=0.05 ;{ }^{\star}=0.10$.

to go ahead with the HCSTC agreement (the opportunity cost of which is to impose a further delay on the smartphone purchase) than individuals adopting a narrower focus on contextual specifics associated with how they might save the money. The effect size is large and meaningful, with, on average, a $33.1 \%(=[2.813-1.882] / 2.813)$ reduction in the likelihood of taking on the HCSTC agreement to fund to going on a stag/hen weekend.

We find evidence of a marginally statistically significant reduction in the likelihood scores across the promotion (2.813) versus prevention (2.255) regulatory focus conditions when a concrete construal level is activated. When an individual is required to think about the narrow contextual specifics of how the objective might be achieved (concrete construal), directing attention towards the avoidance of negative outcomes (prevention focus) leads to a lower likelihood to borrow money via HCSTC to fund another course of action (eg to go on a stag/hen weekend) with an associated opportunity cost (eg a further delay in the purchase of the smartphone) than when attention is directed towards the attainment of positive outcomes (promotion focus). The same is not true when an individual is required to think about why the objective might be achieved (abstract construal). When thinking 
about the narrow contextual specifics of how they might save money to fund the purchase of a new smartphone, individuals whose attention is directed towards avoiding a further delay of six months are less inclined to go ahead with the HCSTC agreement than individuals focused on the positives associated with obtaining the smartphone without a further delay. The effect size is large and meaningful, with, on average, a $19.8 \%(=[2.813-2.255] / 2.813)$ reduction in the likelihood of taking on the HCSTC agreement to fund to going on a stag/hen weekend.

\section{Discussion and conclusions}

There is no doubt that the host of the regulatory changes brought in by the FCA to the HCSTC market has achieved some positive results regarding consumer protection. The FCA reported, in 2017, approximate savings of $£ 150$ million a year on the cost of HCSTC after the cost cap, better affordability assessments, and lower instances of debt problems. ${ }^{126}$ However, these results do not reflect the whole reality of the HCSTC market nor can the changes respond to the constantly evolving business model of HCSTC providers. As demonstrated earlier, the decrease in number of HCSTC consumers seeking help from debt charities was countered by an increase in HCSTC consumers complaints to FSO. Furthermore, HSCTC remains a major source of over-indebtedness in the UK, the rigour of affordability and creditworthiness assessments is still a problematic issue, the majority of HCSTC is offered online which is a challenging regulatory environment and, finally, despite all the regulatory changes the number of HCSTC agreements taken out is on the rise. It seems, therefore, that there is a limit to what these provisions and restrictions can achieve regarding the protection of HCSTC consumers and that the next step in this quest should focus on ways to help those consumers make better choices.

Our research set out to examine if and how attitudes towards the use of HCSTC might be influenced, considering both a simple nudge and a more complex behavioural intervention based on psychological insights. In summary, our findings suggest that such attitudes can be positively influenced, such that intentions to use HCSTC can be reduced via behavioural interventions designed to make people think differently about opportunity costs associated with the use of HCSTC. While construal level has a marginally significant effect, with a lower attitude to the use of HCSTC under abstract than concrete construal, the interaction of construal level and regulatory focus is statistically significant, with economically meaningful shifts in attitudes. Under a promotion focus (where attention is directed towards the purchase, as planned, of a new smartphone), abstract construal (with the emphasis on 'why' one is saving money) is associated with a 33.1\% reduced likelihood of using HCSTC relative to a concrete construal (with the emphasis on 'how' to save). At the margin, based on FCA data as at $2018,{ }^{127}$ this would translate into a reduction in the loans per capita ratio for the North East from 118 per 1000 to just shy of 79 per 1000 , or, for the UK as a whole, a reduction in the total value of loans and amount payable from $£ 1,284,809$ and $£ 2,118,788$ to $£ 859,537$ and $£ 1,417,469$, respectively (all figures in $£ 000$ ).

Conversely, a simple nudge, where prior costs are recalled, may serve to strengthen pre-existing positive attitudes towards the use of HCSTC and has the potential to exacerbate problems rather than ameliorate them. Hence, we urge caution on the part of policy makers and recommend full consideration be given to the potential for unintended and undesirable consequences before behavioural interventions are implemented.

Our findings are rooted in, and indeed provide support for, the psychology literature, with Pennington and Roese ${ }^{128}$ hypothesising that inducing a promotion focus would prompt increased consideration to a temporally distant event, thus suggesting the potential for an interaction between construal level and regulatory focus.

\footnotetext{
${ }^{126} \mathrm{FS} 17 / 2$ : High-cost credit and review of the high-cost short-term credit price cap: https://www.fca.org.uk/publications/ feedback-statements/fs17-2-high-cost-credit (last accessed 14 June 2021).

${ }^{127}$ FCA, above n 112.

${ }^{128}$ Pennington and Roese, above n 117.
} 
In view of the above findings, it can be argued that there is a role for 'libertarian paternalism' to drive further welfare benefits in the HCSTC market. In particular, behavioural interventions designed to emphasise the temporal trade-off between current and future consumption inextricably linked with borrowing decisions, and rooted in psychological theories (for example, construal level theory and regulatory focus), can change attitudes towards the use of HCSTC, even among regular users of such credit, with the potential to prompt behavioural change. Such intervention is not going to be implemented by the HCSTC providers without the regulator mandating for it. For example, requiring providers to start the online application process with such an intervention in order to ensure that those who decide to continue with their application were enabled to make a better credit decision. Arguing in favour of this type of intervention is not completely unrealistic given that similar, albeit less complicated, intervention is already used by the FCA. The use of warnings, which is deeply rooted in the behaviour and psychological literature, ${ }^{129}$ was mandated for by the FCA in relation to HCSTC. All HCSTC providers in the UK must display a credit risk warning in 'a prominent way' in all their communications of financial promotion, including on their website. ${ }^{130}$

With a further review proposed by the FCA in the second half of 2020, and now delayed by the ongoing pandemic, our examination of regulatory change in the HCSTC market and the potential complementary role for behavioural interventions is timely. This work comes at a critical time in the consumer credit market, especially in the HCSTC one, due to the expected rise in demand caused by the Covid-19 pandemic. In April 2020, the FCA implemented a temporary measure to defer HCSTC payments for three months without encountering arrears charges. ${ }^{131}$ Despite its importance, this measure remains temporary and only helps those who already have a HCSTC agreement. The main challenge is yet to come, with unemployment on the rise - mainly among those on low income - and the furlough scheme, albeit extended, not a long-term solution. With the very limited resources made available at the moment, for many of the most affected individuals, HCSTC will become the easier, and probably the only, option. Regulating for behavioural intervention may fruitfully be used to dissuade some potential borrowers from taking this option, and instead prompt them to explore other avenues to fund essential expenditure or abstain in the case of conspicuous consumption.

\footnotetext{
${ }^{129}$ Especially in the context of tobacco consumption, for example, see R Borland et al 'Impact of graphic and text warnings on cigarette packs: finding from four countries over five years' (2009) 18(5) Tobacco Control 358; M Bansal-Travers et al 'The impact of cigarette pack design, descriptors and warning labels on risk perception in the US' (2011) 40(6) American Journal of Preventive Medicine 674; and LF Emery et al 'Affective and cognitive mediators of the impact of cigarette warning labels'(2014) 16(3) Nicotine \& Tobacco Research 263.

${ }^{130}$ 'Warning: late repayment can cause you serious money problems. For help, go to moneyadviceservice.org.uk': FCA Handbook, CONC 3.4.1R.

${ }^{131}$ FCA 'High-cost short-term credit and coronavirus: temporary guidance for firms' (April 2020).
}

Cite this article: Aldohni AK, Duxbury D (2022). Regulating high-cost short-term credit in the UK: is there scope for 'libertarian paternalism' based provisions? Legal Studies 42, 246-270. https://doi.org/10.1017/lst.2021.35 